Article

\title{
Design, Synthesis, and Mechanism of Dihydroartemisinin-Coumarin Hybrids as Potential Anti-Neuroinflammatory Agents
}

\author{
Haonan Yu ${ }^{1,+}{ }^{\oplus}$, Zhuang Hou ${ }^{1,+}$, Xiaoguang Yang ${ }^{1}$, Yanhua Mou ${ }^{2, *}$ and Chun Guo ${ }^{1, *}$ \\ 1 School of Pharmaceutical Engineering, Shenyang Pharmaceutical University, Shenyang 110016, China; \\ yhna380@hotmail.com (H.Y.); houzhuang8@sina.com (Z.H.); Xiaog_yang@163.com (X.Y.) \\ 2 School of Life Sciences and Biological Pharmacy, Shenyang Pharmaceutical University, \\ Shenyang 110016, China \\ * Correspondence: mu_hua_jj@sina.com (Y.M.); chunguo@syphu.edu.cn (C.G.); Tel.: +86-24-4352-0226 (C.G.) \\ + These authors contributed equally to this work.
}

Received: 6 April 2019; Accepted: 24 April 2019; Published: 28 April 2019

check for updates

\begin{abstract}
Cancer patients frequently suffer from cancer-related fatigue (CRF), which is a complex syndrome associated with weakness and depressed mood. Neuroinflammation is one of the major inducers of CRF. The aim of this study is to find a potential agent not only on the treatment of cancer, but also for reducing CRF level of cancer patients. In this study, total-thirty new Dihydroartemisinin-Coumarin hybrids $(\mathrm{DCH})$ were designed and synthesized. The in vitro cytotoxicity against cancer cell lines (HT-29, MDA-MB-231, HCT-116, and A549) was evaluated. Simultaneously, we also tested the anti-neuroinflammatory activity of $\mathrm{DCH}$. DCH could inhibit the activated microglia N9 release of NO, TNF- $\alpha$, and IL-6. The docking analysis was shown that MD-2, the coreceptor of TLR4, might be one of the targets of DCH.
\end{abstract}

Keywords: anticancer; anti-neuroinflammation; coumarin; dihydroartemisinin

\section{Introduction}

Chemotherapy is an important method in the therapy of cancer, but the adverse side effects of anticancer agents should also be focused on. Gastrointestinal injury induced by chemotherapeutic agents could result in bacterial/endotoxin translocation from the gut to the systemic blood circulation [1,2]. The released endotoxin would cause a systemic inflammatory response including neuroinflammation [3]. Cancer patients frequently suffer from cancer-related fatigue (CRF), which is a complex syndrome associated with weakness and depressed mood. Diana M., Norden et al. demonstrated that the neuroinflammation is one of the major reasons which induce CRF [4]. Currently, there were no effective method to reduce CRF [5]. The aim of this study is to find a potential anti-neuroinflammatory agents which might reduce CRF of cancer patients.

Central nervous system (CNS) consists of two major types of cells, nerve cells and glial cells. Microglia is a major glial cell and plays an important role as the resident macrophage population in the CNS [6,7]. There has been wide recognition that the fully activated microglial cells are neurotoxic. They release reactive oxygen species, nitric oxide (NO), tumor necrosis factor-alpha $(\mathrm{TNF}-\alpha)$, and other potentially cytotoxic molecules $[8,9]$. It means that activation of microglia could induce neuroinflammation.

Lipopolysaccharide (LPS), also known as endotoxin, is a natural Toll-like receptor 4 (TLR4) ligand and it is also a potent microglial activator that can trigger the production of inflammatory mediators. TLR-4, a transmembrane receptor, plays a vital role in the initiation and acceleration of the inflammatory response induced by LPS $[10,11]$. TLR4 alone does not directly bind LPS and needs 
the coreceptor MD-2 [12]. MD-2 is linked with the extracellular domain of TLR4 and is indispensable for LPS recognition [13]. MD-2 is a member of the MD-2-related lipid-recognition protein family [14]. MD-2 directly binds to LPS in its hydrophobic cavity with high affinity [15].

Artemisinin and its derivatives have been the first-line antimalarial drug since the late 1990s. Dihydroartemisinin (DHA) is the primary bioactive metabolite of artemisinin and its derivatives, but not artemisinin per se [16]. Additionally, DHA has higher bioavailability and less side effects than artemisinin [17]. Recent research showed that besides antimalarial activity, DHA also exhibits anticancer and anti-inflammatory activity [18-21]. As the anti-inflammatory agent, DHA could decrease LPS-induced protein expression of TLR4 [22].

Coumarins are widely distributed in different parts of plants. There are various pharmacological activities of coumarins, which includes anti-inflammatory $[23,24]$ and anticancer activity $[25,26]$. As the anticancer agents, coumarins were reported to exhibit negligible or mild side effects [27,28]. Substitution at the C-3 or C-4 position of coumarins exhibit good cytotoxic activity in various cancer cell lines [26,29-31]. Additionally, as anti-inflammatory agents, some kinds of coumarins could also target TLR4/MD-2 complex [32,33].

In our previous study, Dihydroartemisinin-Coumarin hybrids $(\mathrm{DCH})$ were designed and synthesized referring to the principle of hybridization [34,35]. Each of them contains coumarin moiety, DHA moiety and a linker. DCH could inhibit HT-29 cells proliferation and arrest the $G_{0} / G_{1}$ phase of HT-29 cells [35]. They could also suppress cancer cell migration, and induce apoptosis and ferroptosis of HT-29 cancer cells [35]. It also has been confirmed that the DCH having 1,2,3-triazole linker generally exhibit better cytotoxicity exhibition than the others [35].

With this background, total-thirty new DCH were designed and synthesized, and the synthetic approaches were shown in Figure 1. All of them contained 1,2,3-triazole linker. We focused on the modifications of positions 3 and 4 of the coumarin moiety. Due to the new synthesized DCH were for the cancer patients, we evaluated the in vitro cytotoxicity against cancer cell lines (HT-29, MDA-MB-231, HCT-116, and A549). In addition, DCH could inhibit the activated N9 cell release of NO, TNF- $\alpha$ and IL-6. Furthermore, to investigate the mechanism of the anti-neuroinflammatory activity, docking analysis was applied. The results might support that the anti-neuroinflammatory activity was related to inhibiting TLR4/MD-2 complex.

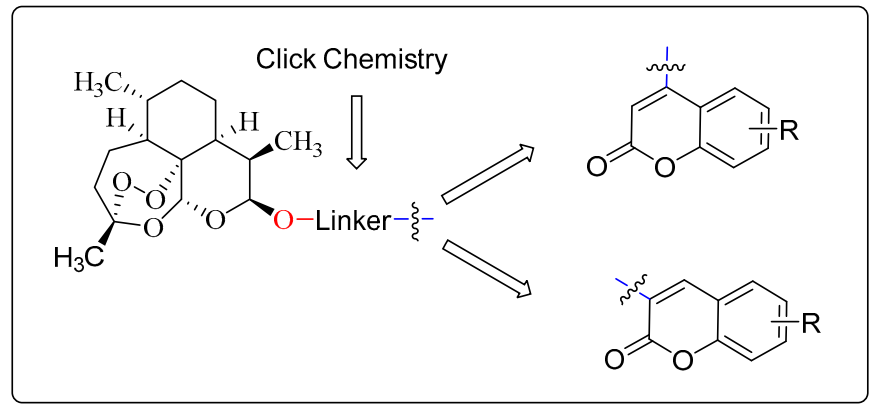

Figure 1. Structures of new designed Dihydroartemisinin-Coumarin hybrids.

\section{Results and Discussion}

\subsection{Chemistry}

The synthesis of the intermediates a-p and I-IV is presented in Scheme 1. The intermediates I and II were obtained by 2-bromoethanol or 3-bromo-1-propanol, with dihydroartemisinin (DHA), respectively, followed by treating the product with sodium azide. The intermediates III and IV were synthesized by propargyl alcohol or 3-butyn-1-ol with DHA, respectively. The required 3-methylcoumarin derivatives were obtained by substitution of salicylaldehyde with propionic anhydride in the presence of sodium propionate and triethylamine. The substituted-3-bromomethylcoumarins were prepared by the radical bromination of 3-methylcoumarin derivatives through the reaction with 
N-Bromosuccinimide (NBS) in the presence of dibenzoylperoxide [36]. The intermediates a-e were synthesized by substituted-3-bromomethylcoumarins via azidation reaction. The required substituted-4-chloromethylcoumarins were prepared by the Pechmann cyclisation [37] of substituted phenols with 4-chloroethylacetoacetate using sulfuric acid as the condensing agent. The intermediates $\mathbf{f}-\mathbf{i}$ were synthesized by substituted-4-chloromethylcoumarin via azidation reaction. To synthesize the intermediates $\mathbf{j}-\mathbf{p}$, several substituted-4-hydroxycoumarin were prepared by condensing the substituted phenol with malonic acid [38]. Then the products were treated with 3-bromo-1-propyne in the presence of potassium carbonate.
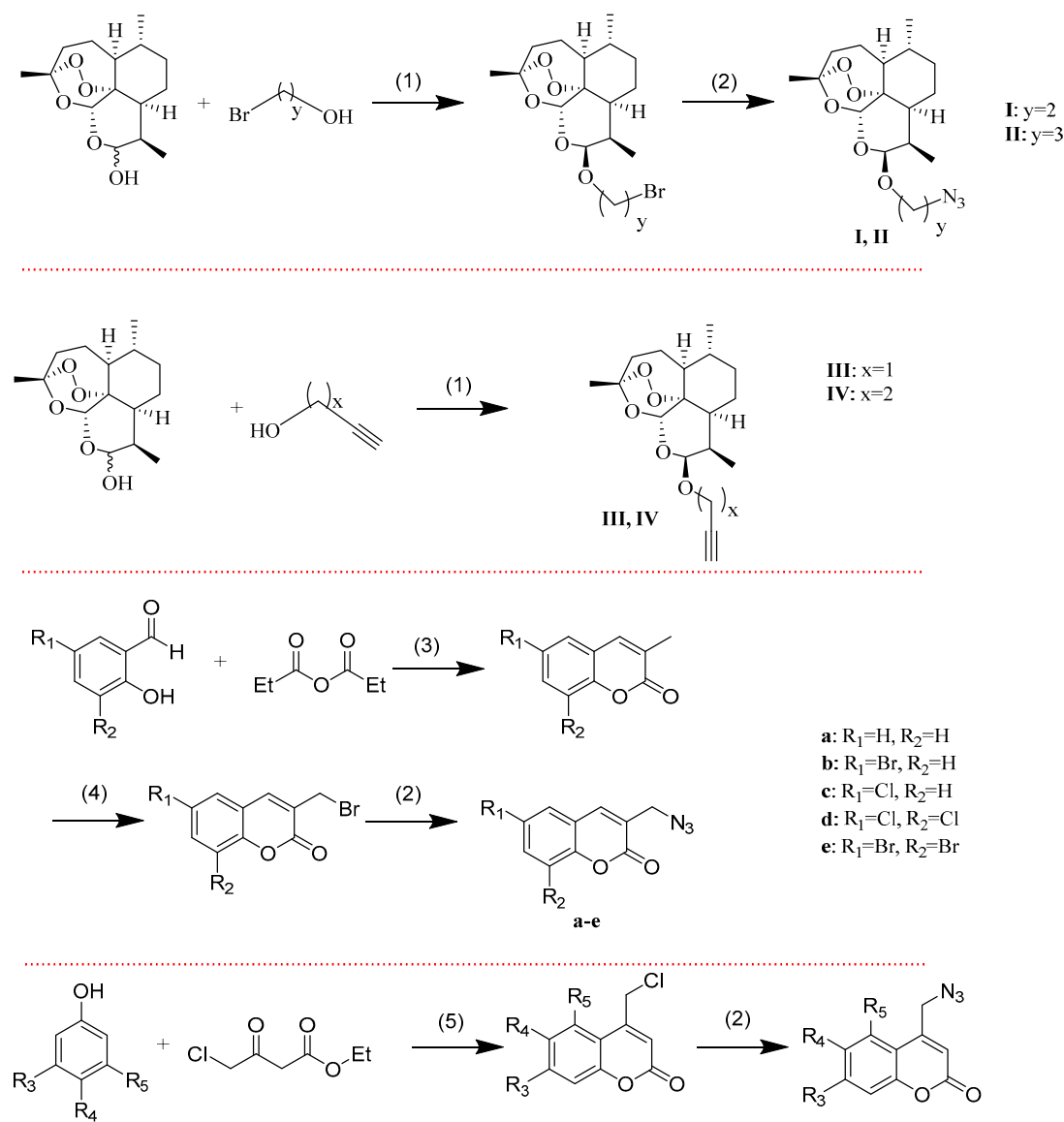

f-i

f: $\mathrm{R}_{3}=\mathrm{OH}, \mathrm{R}_{4}=\mathrm{H}, \mathrm{R}_{5}=\mathrm{H}$ g: $\mathrm{R}_{3}=\mathrm{CH}_{3}, \mathrm{R}_{4}=\mathrm{H}, \mathrm{R}_{5}=\mathrm{CH}_{3}$ h: $\mathrm{R}_{3}=\mathrm{CH}_{3}, \mathrm{R}_{4}=\mathrm{H}, \mathrm{R}_{5}=\mathrm{H}$

i: $\mathrm{R}_{3}=\mathrm{H}, \mathrm{R}_{4}=\mathrm{CH}_{3}, \mathrm{R}_{5}=\mathrm{H}$

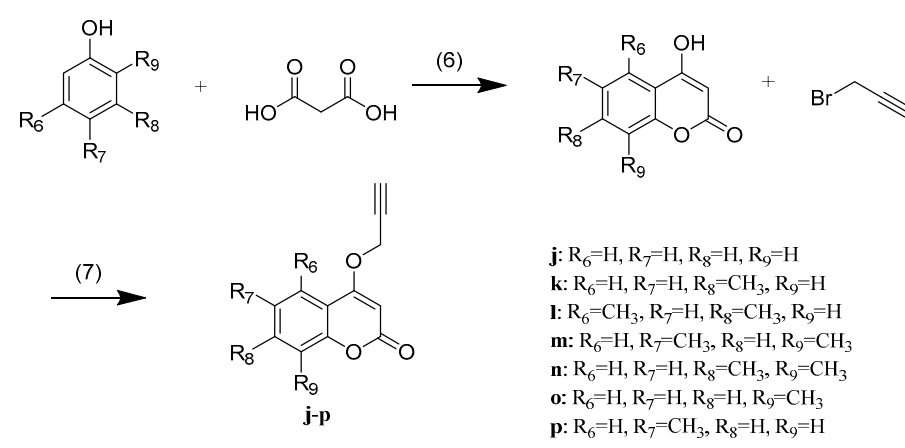

Scheme 1. Synthetic routes of intermediates. Reagents and conditions: (1) $\mathrm{BF}_{3} \cdot \mathrm{Et}_{2} \mathrm{O}, \mathrm{CH}_{2} \mathrm{Cl}_{2}, 0{ }^{\circ} \mathrm{C}$; (2) $\mathrm{NaN}_{3}, \mathrm{DMF}, 6{ }^{\circ} \mathrm{C}$; (3) $\mathrm{CH}_{3} \mathrm{CH}_{2} \mathrm{COONa}, \mathrm{Et}_{3} \mathrm{~N}$, reflux; (4) NBS, $\mathrm{BPO}, \mathrm{CCl}_{4}$, reflux; (5) $70 \% \mathrm{H}_{2} \mathrm{SO}_{4}$, r.t.; (6) $\mathrm{ZnCl}_{2}, \mathrm{POCl}_{3}, 65^{\circ} \mathrm{C}$; and (7) $\mathrm{K}_{2} \mathrm{CO}_{3}, \mathrm{DMF}, 60^{\circ} \mathrm{C}$. 
The synthesis of the desired new compounds was presented in Scheme 2. The target compounds 1a-1e and 2a-2e were obtained by the reaction of the intermediates III or IV with a-e via click chemistry, respectively. The target compounds $\mathbf{3} \mathbf{f}-\mathbf{3 i}$ and $\mathbf{4 f}-\mathbf{4} \mathbf{i}$ were synthesized by intermediates III or IV with $\mathbf{f}-\mathbf{i}$ via click chemistry, respectively. The target compounds $5 \mathbf{j}, 51-50$, and $6 \mathbf{j}-6 \mathbf{p}$ were prepared by the reaction of the intermediates I or II with $\mathbf{j}-\mathbf{p}$ via click chemistry, respectively.
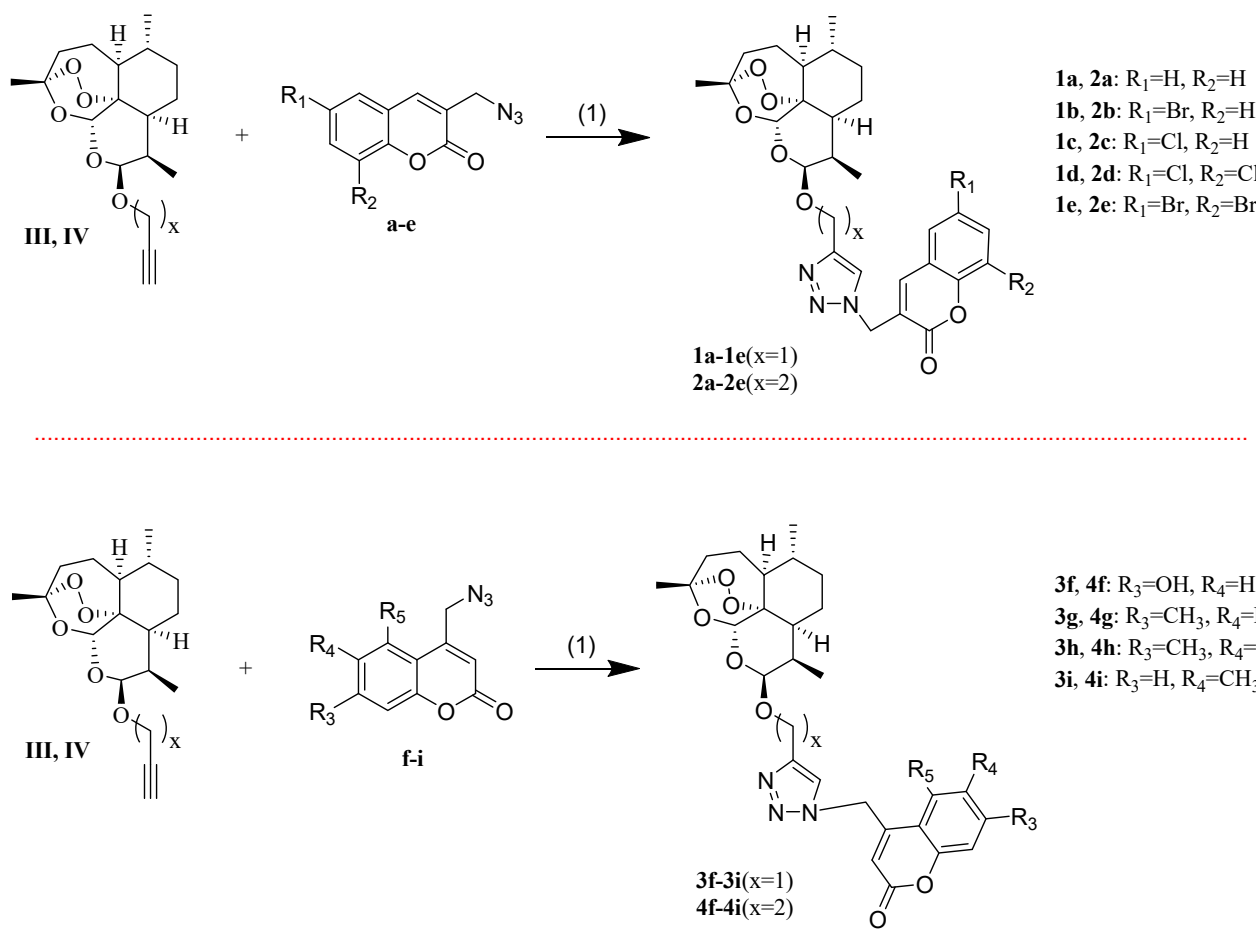

3f, 4f: $\mathrm{R}_{3}=\mathrm{OH}, \mathrm{R}_{4}=\mathrm{H}, \mathrm{R}_{5}=\mathrm{H}$ 3g, 4g: $\mathrm{R}_{3}=\mathrm{CH}_{3}, \mathrm{R}_{4}=\mathrm{H}, \mathrm{R}_{5}=\mathrm{CH}_{3}$ 3h, $\mathbf{4 h}: \mathrm{R}_{3}=\mathrm{CH}_{3}, \mathrm{R}_{4}=\mathrm{H}, \mathrm{R}_{5}=\mathrm{H}$ 3i, 4 i: $\mathrm{R}_{3}=\mathrm{H}, \mathrm{R}_{4}=\mathrm{CH}_{3}, \mathrm{R}_{5}=\mathrm{H}$

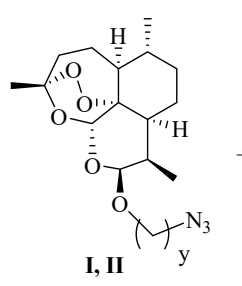<smiles>[R]c1c([R])c([R6])c2c(OCC#C)cc(=O)oc2c1[R6]</smiles><smiles>CCCCCCC</smiles>

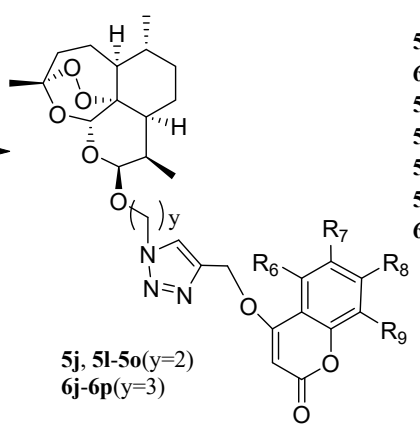

$\mathbf{5 j}, \mathbf{6 j}: \mathrm{R}_{6}=\mathrm{H}, \mathrm{R}_{7}=\mathrm{H}, \mathrm{R}_{8}=\mathrm{H}, \mathrm{R}_{9}=\mathrm{H}$ 6k: $\mathrm{R}_{6}=\mathrm{H}, \mathrm{R}_{7}=\mathrm{H}, \mathrm{R}_{8}=\mathrm{CH}_{3}, \mathrm{R}_{9}=\mathrm{H}$ 5l, 6l: $\mathrm{R}_{6}=\mathrm{CH}_{3}, \mathrm{R}_{7}=\mathrm{H}, \mathrm{R}_{8}=\mathrm{CH}_{3}, \mathrm{R}_{9}=\mathrm{H}$ 5m, 6m: $\mathrm{R}_{6}=\mathrm{H}, \mathrm{R}_{7}=\mathrm{CH}_{3}, \mathrm{R}_{8}=\mathrm{H}, \mathrm{R}_{9}=\mathrm{CH}_{3}$ 5n, 6n: $\mathrm{R}_{6}=\mathrm{H}, \mathrm{R}_{7}=\mathrm{H}, \mathrm{R}_{8}=\mathrm{CH}_{3}, \mathrm{R}_{9}=\mathrm{CH}_{3}$ 5o, 6o: $\mathrm{R}_{6}=\mathrm{H}, \mathrm{R}_{7}=\mathrm{H}, \mathrm{R}_{8}=\mathrm{H}, \mathrm{R}_{9}=\mathrm{CH}_{3}$ 6p: $\mathrm{R}_{6}=\mathrm{H}, \mathrm{R}_{7}=\mathrm{CH}_{3}, \mathrm{R}_{8}=\mathrm{H}, \mathrm{R}_{9}=\mathrm{H}$

Scheme 2. Synthetic routes of target compounds. Reagents and conditions: (1) CuI, triethylamine, dichloromethane, r.t.

\subsection{Biological Assay}

\subsubsection{In Vitro Cytotoxic Activity of the Compounds}

As the anti-neuroinflammatory agents for cancer patients, all newly synthesized compounds were evaluated in vitro for antitumor activity against human breast cancer cell line MDA-MB-231, colorectal cancer cells HT-29 and HCT-116, and lung cancer cell line A549 by using the standard MTT method, respectively. Doxorubicin (DOX) and DHA were used as the reference standard. Additionally, owing to the rapid proliferation, the tumor cells actually was always in hypoxia condition. Therefore, the in vitro cytotoxicity was evaluated in two different conditions (hypoxia and normoxia). All data are summarized in Table 1. Most of the target compounds exhibited moderate activities against the tested cell lines and they showed a general promotion under hypoxia conditions. 
The structure-activity relationship was evaluated: (i) the series of compounds $\mathbf{5}$ and $\mathbf{6}$ generally exhibited better cytotoxicity activity than that of the series of compounds 3 and 4 , which indicated that the 4-oxygen group in the coumarin moiety as a part of linker could improve the antitumor activity; (ii) although compounds 3 and 4 did not exhibit good activity against three cell lines (MDA-MB-231, HCT-116, and A549), they showed good activity against HT-29 like the other derivatives. Therefore, 4-methyl group in the coumarin moiety could improve the selectivity of DCH against HT-29.

In addition, almost all of the target compounds exhibited good cytotoxicity activity against HT-29. Therefore, HT-29 was selected for the next explorations.

Table 1. $\mathrm{IC}_{50}(\mu \mathrm{M})$ of tested samples in MDA-MB-231, HT-29, HCT-116, and A549 cell lines.

\begin{tabular}{|c|c|c|c|c|c|c|c|c|}
\hline & \multicolumn{2}{|c|}{ HT-29 } & \multicolumn{2}{|c|}{ MDA-MB-231 } & \multicolumn{2}{|c|}{ НCT-116 } & \multicolumn{2}{|c|}{ A549 } \\
\hline & Hypoxia & Normoxia & Hypoxia & Normoxia & Hypoxia & Normoxia & Hypoxia & Normoxia \\
\hline DOX & $<0.1$ & 0.11 & 0.69 & 1.37 & $>2$ & 1.29 & $>2$ & $>2$ \\
\hline DHA & 11.74 & 51.10 & 45.93 & $>100$ & 25.89 & 10.33 & $>100$ & $>100$ \\
\hline $1 a$ & 14.29 & 18.40 & 30.47 & 64.97 & 49.79 & 48.90 & 53.87 & 83.48 \\
\hline $1 b$ & 13.14 & 21.35 & $>100$ & $>100$ & $>100$ & $>100$ & $>100$ & $>100$ \\
\hline 1c & 26.37 & 35.41 & 32.26 & $>100$ & 40.38 & 60.30 & 48.70 & 73.49 \\
\hline $1 d$ & 13.34 & 14.94 & 33.93 & 68.85 & 48.61 & 60.01 & 45.42 & 53.34 \\
\hline $1 e$ & 26.95 & 15.32 & 45.46 & 77.89 & $>100$ & 54.45 & 59.75 & $>100$ \\
\hline $2 a$ & 19.42 & $>100$ & $>100$ & $>100$ & $>100$ & $>100$ & $>100$ & $>100$ \\
\hline $2 b$ & 12.09 & 9.75 & 36.86 & 37.74 & $>100$ & 55.99 & 60.16 & $>100$ \\
\hline $2 c$ & 19.61 & 17.46 & 32.47 & 43.98 & 64.37 & 49.48 & 66.87 & 87.15 \\
\hline $2 d$ & 30.81 & 19.54 & 47.92 & 88.46 & 46.51 & 53.19 & 69.67 & 96.48 \\
\hline $2 e$ & 13.92 & 38.52 & 44.14 & $>100$ & 86.49 & 94.16 & 79.37 & $>100$ \\
\hline $3 f$ & 15.46 & 37.83 & 63.07 & $>100$ & 67.74 & $>100$ & 98.00 & $>100$ \\
\hline $3 g$ & 15.86 & 23.89 & $>100$ & $>100$ & $>100$ & $>100$ & $>100$ & $>100$ \\
\hline $3 h$ & 32.04 & $>100$ & $>100$ & $>100$ & $>100$ & $>100$ & $>100$ & $>100$ \\
\hline $3 i$ & 8.57 & 16.36 & 22.81 & $>100$ & $>100$ & 64.99 & 62.27 & $>100$ \\
\hline $4 f$ & 11.30 & 32.30 & 78.79 & $>100$ & $>100$ & $>100$ & $>100$ & $>100$ \\
\hline $4 \mathrm{~g}$ & 9.33 & 13.85 & 22.71 & $>100$ & 25.65 & 34.50 & $>100$ & $>100$ \\
\hline $4 \mathrm{~h}$ & 56.35 & $>100$ & $>100$ & $>100$ & $>100$ & $>100$ & $>100$ & $>100$ \\
\hline $4 i$ & 39.02 & $>100$ & $>100$ & $>100$ & $>100$ & $>100$ & $>100$ & $>100$ \\
\hline $5 \mathbf{j}$ & 12.25 & 30.03 & 69.41 & 100.00 & $>100$ & 77.20 & $>100$ & $>100$ \\
\hline 51 & 3.76 & 2.78 & $>100$ & $>100$ & $>100$ & $>100$ & $>100$ & $>100$ \\
\hline $5 \mathrm{~m}$ & 5.89 & 12.88 & 13.04 & 14.17 & 44.81 & 62.82 & 1.282 & 2.670 \\
\hline $5 n$ & 8.90 & 10.19 & 11.68 & 11.04 & 32.92 & 25.64 & 2.443 & 2.107 \\
\hline 50 & 21.25 & 16.09 & 16.54 & 37.41 & 38.49 & 29.69 & 45.06 & 50.37 \\
\hline $6 j$ & 7.42 & 10.49 & 33.40 & 67.42 & 32.84 & 25.90 & 49.03 & 53.37 \\
\hline $6 k$ & 5.32 & 6.85 & 14.46 & 38.56 & 33.70 & 28.13 & 9.49 & 14.92 \\
\hline 61 & 3.40 & 8.41 & 6.85 & 1.17 & 27.92 & 26.90 & 9.78 & 6.88 \\
\hline $6 \mathrm{~m}$ & 5.90 & 22.43 & 18.74 & 24.64 & 93.53 & 42.05 & 20.14 & 27.87 \\
\hline $6 n$ & 4.19 & 9.16 & 10.84 & 13.35 & 33.74 & 22.51 & 0.039 & 30.40 \\
\hline 60 & 29.02 & 81.57 & 18.57 & 47.65 & 42.35 & 12.09 & 39.92 & 78.07 \\
\hline $6 p$ & 12.48 & 7.49 & 10.33 & 22.08 & 38.05 & 35.33 & 18.82 & 18.85 \\
\hline
\end{tabular}

\subsubsection{Morphological Changes and Effect of Compound 5n on Cell Viability}

As shown in A-F of Figure 2, there showed a concentration-dependent cell death after treatment with compound $5 \mathrm{n}$ for $48 \mathrm{~h}$. As the concentration up to $100 \mu \mathrm{M}$, the compound $5 \mathrm{n}$ could obviously inhibit the proliferation of HT-29. As shown in the $(G)$ of Figure 2, after HT-29 cells were treated with different concentrations of $5 \mathrm{n}$ for $48 \mathrm{~h}$, the cell viability decreased in a dose-dependent manner. 


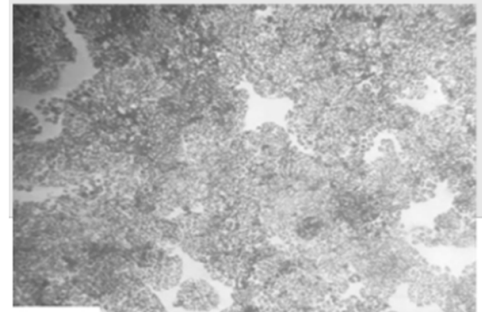

A

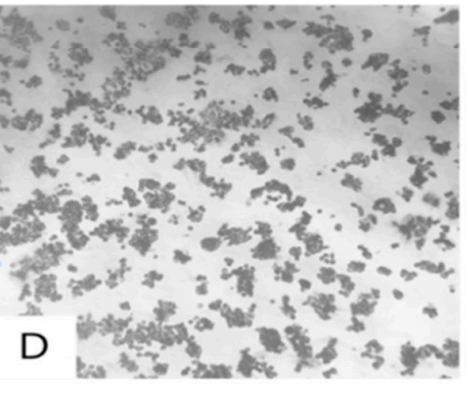

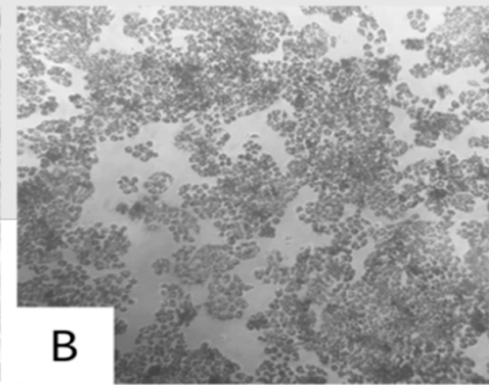
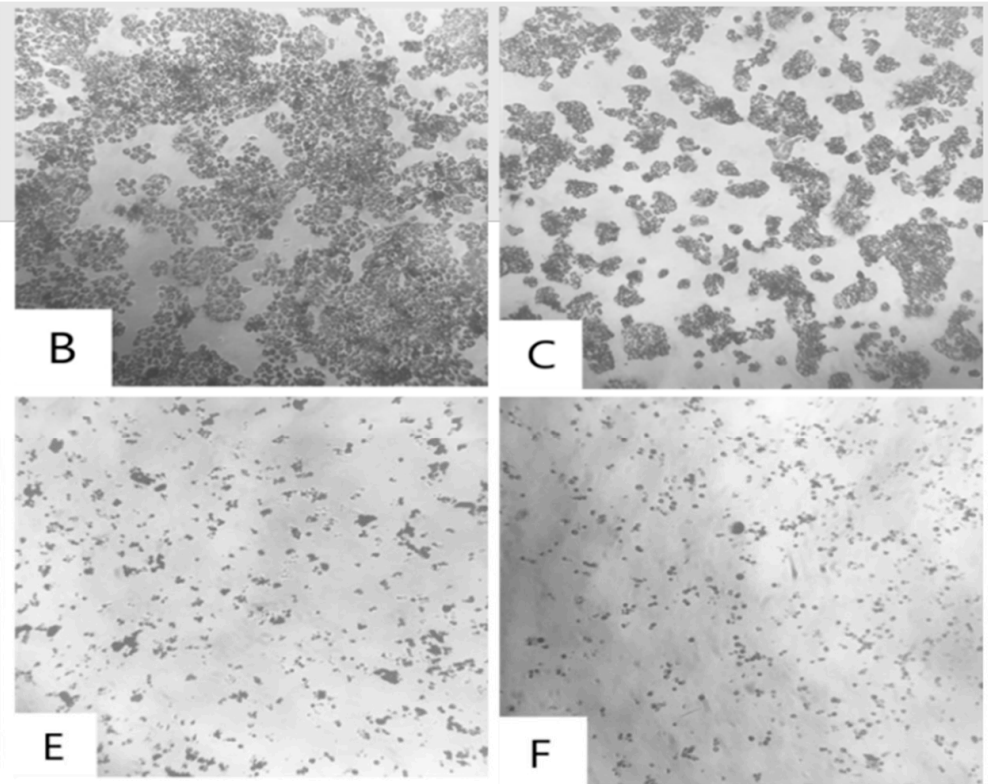

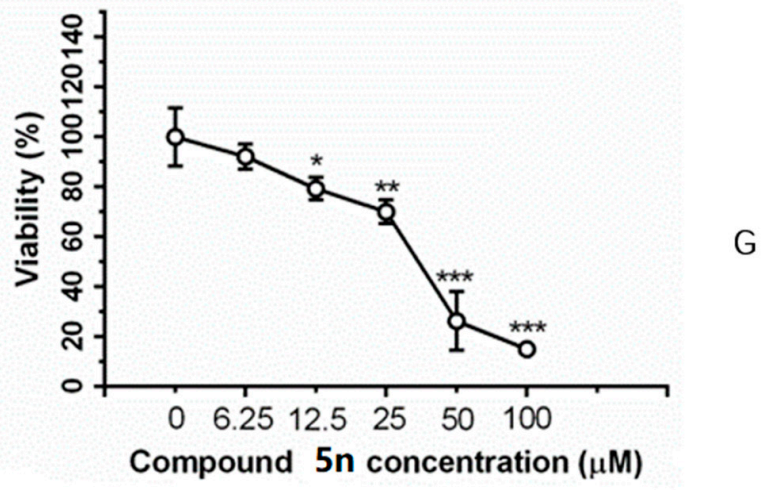

Figure 2. Inhibition of compound $\mathbf{5 n}$ on cell viability in HT-29 cells by MTT staining. Cells were treated with (A) $0 \mu \mathrm{M},(\mathbf{B}) 6.25 \mu \mathrm{M},(\mathbf{C}) 12.5 \mu \mathrm{M},(\mathbf{D}) 25.0 \mu \mathrm{M},(\mathbf{E}) 50.0 \mu \mathrm{M}$, and (F) $100.0 \mu \mathrm{M}$ compound 5 n for $48 \mathrm{~h}$. Representative images were shown; 200×. (G) Cells were treated with 6.25, 12.5, 25, 50 , and $100 \mu \mathrm{M}$ compound $5 \mathrm{n}$ for $48 \mathrm{~h}$. Data were shown as mean $\pm \mathrm{SD}$. ${ }^{*} p<0.05,{ }^{* *} p<0.01$ and *** $p<0.001$ compared with group $0 \mu \mathrm{M}$.

\subsubsection{Anti-Neuroinflammatory Activity}

The anti-neuroinflammatory activity of $\mathrm{DCH}$ was evaluated and then the representative compounds were selected for the further study. As shown in Table 2, murine microglial N9 cells were treated with $1 \mu \mathrm{g} / \mathrm{mL}$ LPS for $48 \mathrm{~h}$ and the NO level in the medium was measured as the preliminary screening. Most of the tested compounds exhibited good anti-inflammatory activity, and especially the $\mathrm{IC}_{50}$ of some compounds were even less than $1 \mu \mathrm{M}$. Among them, compound $\mathbf{5 n}$ had the best activity and the $\mathrm{IC}_{50}$ reached $0.22 \mu \mathrm{M}$. In addition, in order to exclude the death influence, MTT-IC20 of all the compounds were measured. The results showed that $\mathrm{DCH}$ did not exhibit cytotoxic activity in N9 cells. The exact reason was still unclear, but we supposed that it might be related to the homeostasis of cells. The tumor cells actually were always in hypoxia condition, in which DCH could promote the cytotoxic activity against tumor cells. In brief, DCH could reduce the release of NO caused by LPS-induced microglial cells. 
Table 2. $\mathrm{IC}_{50}$ of tested samples in LPS-induced N9 cells for the inhibition of NO; $\mathrm{IC}_{20}$ of tested samples in N9 cells for cytotoxic activity.

\begin{tabular}{|c|c|c|}
\hline Compound. & NO-IC $50(\mu \mathrm{M})$ & MTT-IC $_{20}(\mu \mathrm{M})$ \\
\hline $1 a$ & 1.46 & $>10$ \\
\hline $1 b$ & $>10$ & $>10$ \\
\hline $1 c$ & 5.33 & $>10$ \\
\hline 1d & 1.60 & $>10$ \\
\hline $1 e$ & 0.48 & $>10$ \\
\hline $2 a$ & 0.97 & $>10$ \\
\hline $2 b$ & 0.64 & $>10$ \\
\hline $2 c$ & 2.66 & $>10$ \\
\hline $2 d$ & 1.35 & $>10$ \\
\hline $2 e$ & 0.94 & $>10$ \\
\hline $3 \mathrm{f}$ & 0.37 & $>10$ \\
\hline $3 g$ & $>10$ & $>10$ \\
\hline $3 h$ & $>10$ & $>10$ \\
\hline $3 \mathbf{i}$ & 0.72 & $>10$ \\
\hline $4 \mathrm{f}$ & 2.03 & $>10$ \\
\hline $4 \mathrm{~g}$ & 1.36 & $>10$ \\
\hline $4 h$ & 5.69 & $>10$ \\
\hline $4 i$ & $>10$ & $>10$ \\
\hline $5 \mathbf{j}$ & 1.59 & $>10$ \\
\hline 51 & 3.36 & 7.13 \\
\hline $5 \mathrm{~m}$ & 1.08 & 1.04 \\
\hline $5 n$ & 0.22 & 2.44 \\
\hline 50 & 0.57 & $>10$ \\
\hline $6 j$ & 0.29 & $>10$ \\
\hline $6 \mathrm{k}$ & 1.91 & $>10$ \\
\hline 61 & 0.52 & $>10$ \\
\hline $6 \mathrm{~m}$ & 5.80 & $>10$ \\
\hline $6 n$ & 1.13 & 6.53 \\
\hline 60 & 1.43 & $>10$ \\
\hline $6 p$ & 1.42 & $>10$ \\
\hline DHA & 1.58 & $>10$ \\
\hline Minocycline & $>10$ & $>10$ \\
\hline
\end{tabular}

NO Capture Capability

Sodium nitroprusside (SNP) is a NO donor. In this experiment, the reason of the DCH reducing NO level was preliminary explored. As shown in Figure 3, the results showed that the compounds only partially reduced NO levels by direct NO capture. That means the main reason of the NO level reduction is due to species-specific effect.

\section{SNP}

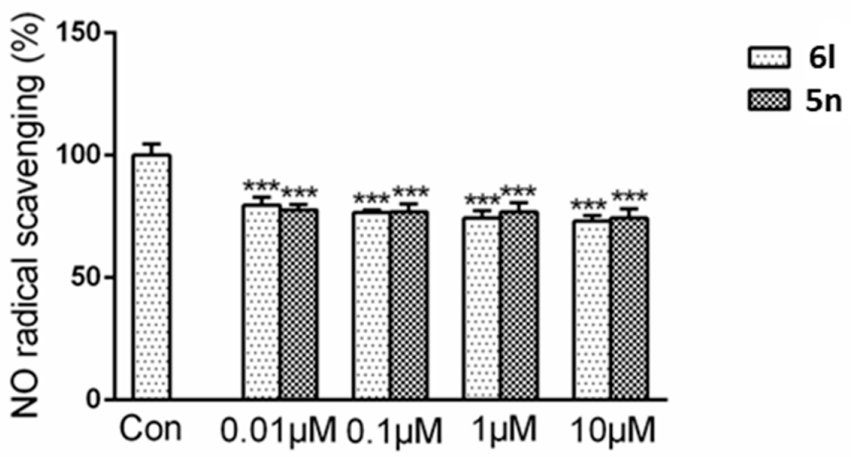

Figure 3. Compound 61 and $5 \mathrm{n}$ had NO radical scavenging activity. $61(0.01 \mu \mathrm{M}, 0.1 \mu \mathrm{M}, 1 \mu \mathrm{M}$, and $10 \mu \mathrm{M})$ or $5 \mathrm{n}(0.01 \mu \mathrm{M}, 0.1 \mu \mathrm{M}, 1 \mu \mathrm{M}$, and $10 \mu \mathrm{M})$ was added to a concentration of $0.5 \mathrm{mM}$ SNP solution. After reacted for $1 \mathrm{~h}$ under normal sun light at room temperature, Griess reagent was added and the optical density was observed at $540 \mathrm{~nm}$. Data were shown as mean \pm SD. ${ }^{* * *} p<0.001$ compared with control group. 
Effect of Representative Compounds on TNF- $\alpha$ and IL-6 Release

As shown in Table 3, four kinds of DCH were involved to measure the effect on the release of TNF- $\alpha$ and IL- 6 from the microglia cells which induced by LPS for $48 \mathrm{~h}$. The results showed that compounds $\mathbf{2 b}, \mathbf{2 c}, \mathbf{5 n}$, and $\mathbf{6} \mathbf{p}$ could inhibit the release of TNF- $\alpha$ with the inhibition rate of $22 \%$ to $32 \%$ and the release of IL-6 with the inhibition rate of $26 \%$ to $43 \%$. The results indicated that the inhibition effect of DCH on NO release was not only by nonspecific effects, but also by slightly influencing the synthesis and release of upstream inflammatory pathway.

Table 3. The inhibition of compounds $(1 \mu \mathrm{M})$ on cytokines release $(48 \mathrm{~h})$ of the murine microglial cell line N9 induced by lipopolysaccharide (LPS) $(1 \mu \mathrm{g} / \mathrm{mL})$.

\begin{tabular}{|c|c|c|c|c|}
\hline Group & TNF- $\alpha(\mathrm{pg} / \mathrm{mL})$ & Inhibition (\%) & IL-6 (pg/mL) & Inhibition (\%) \\
\hline Con & $155.54 \pm 79.61$ & - & 0 & - \\
\hline LPS & $4455.87 \pm 518.24^{\#}$ & - & $1154.44 \pm 148.48^{\#}$ & - \\
\hline $2 b$ & $3285.99 \pm 1062.40$ & 27.20 & $797.52 \pm 140.74$ * & 30.92 \\
\hline $2 c$ & $3077.03 \pm 375.48$ & 32.06 & $850.24 \pm 112.47$ & 26.35 \\
\hline $5 n$ & $3508.08 \pm 368.72$ & 22.04 & $656.75 \pm 79.49^{* *}$ & 43.11 \\
\hline $6 p$ & $3451.29 \pm 646.50$ & 23.36 & $747.80 \pm 125.56 *$ & 35.22 \\
\hline
\end{tabular}

\section{Docking Analysis}

Toll-like receptor 4 (TLR4) and its coreceptor-MD-2-are the target of LPS, which could influence innate immune response to release potentially cytotoxic molecules. MD-2 is linked with the extracellular domain of TLR4 and is indispensable for LPS recognition [13]. Therefore, this docking analysis was applied to explore whether or not the target compounds inhibit MD-2 to reduce the release of inflammatory mediators. Umeharu Ohto et al. [39] had revealed the crystal structure of mouse TLR4/MD-2/LPS complex, which was shown in Figure 4. In their study, MD-2 directly bound to LPS in its hydrophobic cavity with high affinity. With this background, compound 5 n was used as the ligand to explore the relationship between DCH and TLR4/MD-2/LPS complex. As shown in Figure 5, compound 5 n could integrate closely with the hydrophobic cavity of MD-2, which is the important TLR4/MD-2/LPS binding position. That means the DCH might disturb the interactions between LPS and TLR4/MD-2 complex. The minimum binding energy of $(\Delta \mathrm{G})$ is $-10.08 \mathrm{kcal} / \mathrm{mol}$. Given to this result, we supposed TLR4/MD-2 complex is likely to be one of the drug targets of DCH.

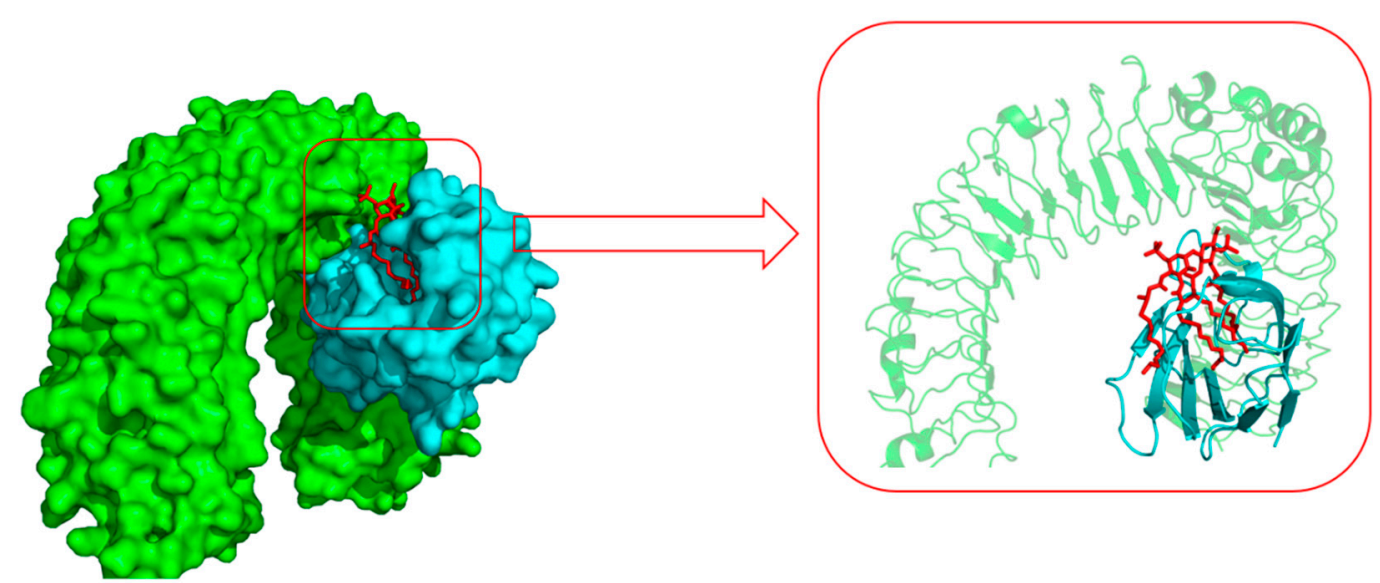

Figure 4. The surface representation of LPS (red) and Toll-like receptor 4 (TLR4) (green)/MD-2 (cyan) binding pocket (PDB: 3VQ2). 
A

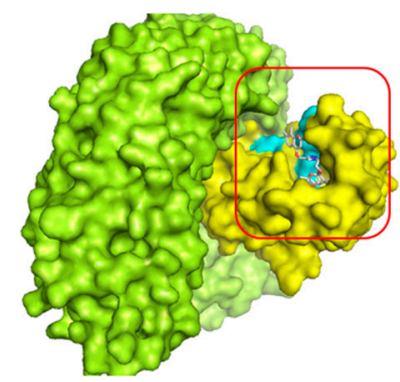

C

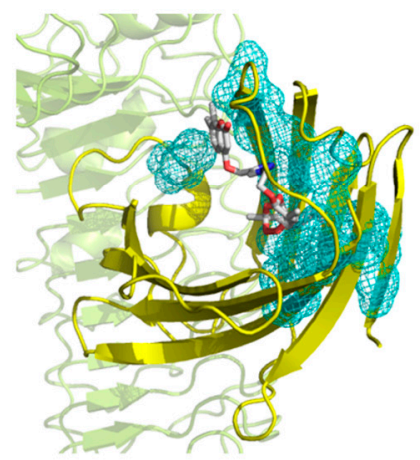

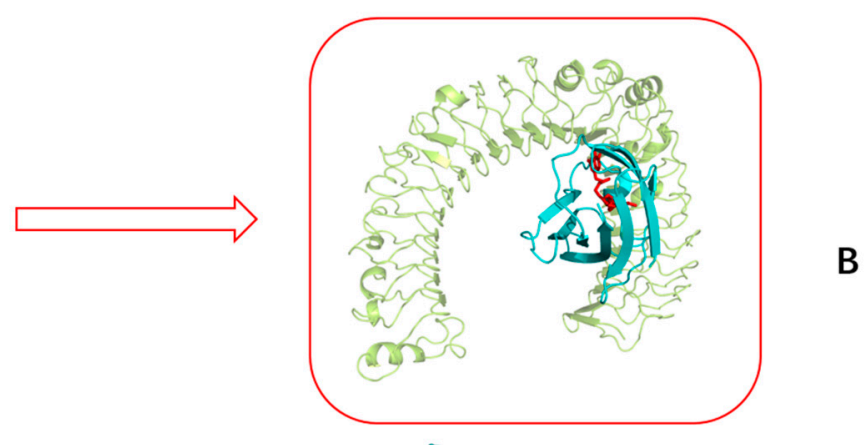

B

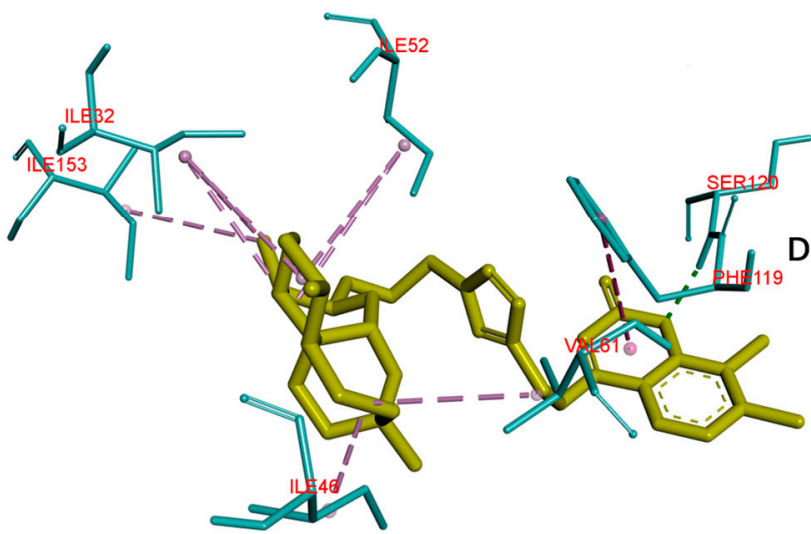

Figure 5. Interaction diagrams of the selected docked conformations of compound 5n to TLR4/MD-2 complex. (A) The surface representation of compound 5n and TLR4 (limon)/MD-2 (yellow) binding pocket. (B) The magnified representation of compound 5n (red) and TLR4 (limon)/MD-2 (cyan) binding pocket. (C) The interface of compound 5n and TLR4/MD-2 complex; (D) 3D ligand interactions diagram. Dotted line; pink: alkyl hydrophobic; blue: pi hydrophobic; green: hydrogen bond.

\section{Conclusions}

Total-thirty new DCH were designed and synthesized. Most of the target compounds exhibited moderate activities against the tested cell lines and they showed a general promotion under hypoxia conditions. Meanwhile, the new potential activity of $\mathrm{DCH}$ was found that $\mathrm{DCH}$ could exhibit anti-neuroinflammatory activity. DCH could inhibit the release of NO, TNF- $\alpha$, and IL-6, which were induced by LPS. The docking analysis was shown that MD-2, the coreceptor of TLR4, might be one of the targets of DCH. Additionally, DCH could also reduce NO levels by direct NO capture. In brief, $\mathrm{DCH}$ were the potential anti-neuroinflammatory agents which might reduce CRF of cancer patients.

\section{Experimental Section}

\subsection{Chemistry}

Unless otherwise specified, all solvents and reagents were commercially available and used without further purification. Analytical TLC was performed using silica gel precoated GF254 plates. The ${ }^{1} \mathrm{H}-\mathrm{NMR}$ and ${ }^{13} \mathrm{C}-\mathrm{NMR}$ spectra were recorded at $600 \mathrm{MHz}$ and $150 \mathrm{MHZ}$ on a Bruker AV-400 spectrometer (Bruker Bioscience, Billerica, $\mathrm{MA}, \mathrm{USA}$ ), using $\mathrm{CDCl}_{3}$ as solvent with tetramethylsilane as the internal standard. NMR spectra were analyzed using MestReNova. High-resolution mass spectra (HRMS) were measured using an Agilent Accurate-Mass Q-TOF 6530 (Agilent, Santa Clara, CA, USA) instrument in ESI mode. The ${ }^{1} \mathrm{H}-\mathrm{NMR}$ and ${ }^{13} \mathrm{C}-\mathrm{NMR}$ spectra of synthesized compounds, please see the supplementary materials. 


\subsubsection{General Procedure for the Synthesis of Compounds $1 \mathbf{a}-\mathbf{1 e}$ and $\mathbf{2 a}-\mathbf{2 e}$}

Substituted coumarin (a-e) (10 mmol), substituted DHA (III or IV) (10 mmol), and triethylamine $(10 \mathrm{mmol})$ were dissolved in $20 \mathrm{~mL} \mathrm{CH}_{2} \mathrm{Cl}_{2}$. In addition, $\mathrm{CuI}(100 \mathrm{mg})$ was added and the reaction mixture was stirred at room temperature for $8 \mathrm{~h}$ under the protection of nitrogen. The mixture was filtered, washed with water, dried over $\mathrm{Na}_{2} \mathrm{SO}_{4}$ and evaporated to dryness. The crude product was purified through column chromatography.

3-((4-((10S)-dihydroartemisininoxy)methyl-1H-1,2,3-triazol-1-yl)-methyl)-2H-1-chromen-2-one (1a) White solid; m.p. $73-75{ }^{\circ} \mathrm{C}$; yield 52\%; ${ }^{1} \mathrm{H} \mathrm{NMR}\left(600 \mathrm{MHz}, \mathrm{CDCl}_{3}\right) \delta(\mathrm{ppm}): 7.77(\mathrm{~s}, 1 \mathrm{H}), 7.68(\mathrm{~s}, 1 \mathrm{H}), 7.56(\mathrm{t}$, $J=7.9 \mathrm{~Hz}, 1 \mathrm{H}), 7.47(\mathrm{~d}, J=7.7 \mathrm{~Hz}, 1 \mathrm{H}), 7.34(\mathrm{~d}, J=8.4 \mathrm{~Hz}, 1 \mathrm{H}), 7.30(\mathrm{t}, J=7.6 \mathrm{~Hz}, 1 \mathrm{H}), 5.47(\mathrm{~s}, 2 \mathrm{H}), 5.39$ $(\mathrm{s}, 1 \mathrm{H}), 4.94(\mathrm{~d}, J=12.6 \mathrm{~Hz}, 1 \mathrm{H}), 4.92(\mathrm{~d}, J=3.5 \mathrm{~Hz}, 1 \mathrm{H}), 4.68(\mathrm{~d}, J=12.6 \mathrm{~Hz}, 1 \mathrm{H}), 2.67-2.60(\mathrm{~m}, 1 \mathrm{H})$, 2.38-2.31 (m, 1H), 2.01-1.97 (m, 1H), 1.85-1.81 (m, 1H), 1.77-1.68 (m, 3H), $1.59(\mathrm{dd}, J=13.2,3.4 \mathrm{~Hz}, 1 \mathrm{H})$, $1.46-1.43(\mathrm{~m}, 1 \mathrm{H}), 1.41(\mathrm{~s}, 3 \mathrm{H}), 1.31-1.18(\mathrm{~m}, 1 \mathrm{H}), 1.26-1.16(\mathrm{~m}, 2 \mathrm{H}), 0.91(\mathrm{~d}, J=6.3 \mathrm{~Hz}, 3 \mathrm{H}), 0.88(\mathrm{~d}$, $J=7.3 \mathrm{~Hz}, 3 \mathrm{H}) ;{ }^{13} \mathrm{C} \mathrm{NMR}\left(150 \mathrm{MHz}, \mathrm{CDCl}_{3}\right) \delta$ (ppm): 159.64, 152.65, 144.62, 141.31, 131.46, 127.30, 123.92, 122.67, 121.84, 117.53, 115.71, 103.10, 100.77, 86.93, 80.06, 76.22, 76.01, 75.80, 60.70, 51.47, 47.97, 43.33, 36.33, 35.36, 33.52, 29.78, 25.09, 23.59, 23.41, 19.30, 11.99; ESI-HRMS [M + Na] ${ }^{+}:(\mathrm{m} / z)$ Calcd. for $\mathrm{C}_{28} \mathrm{H}_{33} \mathrm{~N}_{3} \mathrm{O}_{7} \mathrm{Na}: 546.2216$. Found: 546.2181.

6-bromo-3-((4-((10S)-dihydroartemisininoxy)methyl-1H-1,2,3-triazol-1-yl)-methyl)-2H-1-chromen-2-one (1b) White solid; m.p. $78-80{ }^{\circ} \mathrm{C}$; yield $48 \%$; ${ }^{1} \mathrm{H}$ NMR $\left(600 \mathrm{MHz}, \mathrm{CDCl}_{3}\right) \delta$ (ppm): $7.75(\mathrm{~s}, 1 \mathrm{H}), 7.64(\mathrm{dd}$, $J=8.8,2.3 \mathrm{~Hz}, 1 \mathrm{H}), 7.61(\mathrm{~d}, J=2.3 \mathrm{~Hz}, 1 \mathrm{H}), 7.55(\mathrm{~s}, 1 \mathrm{H}), 7.24(\mathrm{~d}, J=8.8 \mathrm{~Hz}, 1 \mathrm{H}), 5.47(\mathrm{~s}, 2 \mathrm{H}), 5.39$ $(\mathrm{s}, 1 \mathrm{H}), 4.94(\mathrm{~d}, J=12.7 \mathrm{~Hz}, 1 \mathrm{H}), 4.93(\mathrm{~d}, J=3.5 \mathrm{~Hz}, 1 \mathrm{H}), 4.69(\mathrm{~d}, J=12.8 \mathrm{~Hz}, 1 \mathrm{H}), 2.67-2.63(\mathrm{~m}, 1 \mathrm{H})$, 2.38-2.33 (m, 1H), 2.03-1.99 (m, 1H), 1.86-1.82 (m, 1H), 1.75-1.70 (m, 2H), 1.62-1.58 (m, 2H), $1.42(\mathrm{~s}$, $3 \mathrm{H}), 1.31-1.19(\mathrm{~m}, 4 \mathrm{H}), 0.92(\mathrm{~d}, J=6.3 \mathrm{~Hz}, 3 \mathrm{H}), 0.89(\mathrm{~d}, J=7.4 \mathrm{~Hz}, 3 \mathrm{H}) ;{ }^{13} \mathrm{C} \mathrm{NMR}\left(150 \mathrm{MHz}, \mathrm{CDCl}_{3}\right) \delta$ (ppm): 158.90, 151.42, 144.74, 139.67, 134.18, 129.51, 123.17, 122.67, 119.00, 117.43, 116.53, 103.12, 100.87, $86.95,80.06,76.20,75.99,75.78,60.76,51.46,47.82,43.32,36.36,35.36,33.52,29.79,25.10,23.62,23.42$, 19.30, 12.00; ESI-HRMS [M + Na] ${ }^{+}:(m / z)$ Calcd. for $\mathrm{C}_{28} \mathrm{H}_{32} \mathrm{BrN}_{3} \mathrm{O}_{7} \mathrm{Na}$ : 624.1321. Found: 624.1264.

6-chloro-3-((4-((10S)-dihydroartemisininoxy)methyl-1H-1,2,3-triazol-1-yl)-methyl)-2H-1-chromen-2-one (1c) White solid; m.p. 93-95 ${ }^{\circ} \mathrm{C}$; yield 41\%; ${ }^{1} \mathrm{H}$ NMR (600 MHz, $\left.\mathrm{CDCl}_{3}\right) \delta$ (ppm): $7.75(\mathrm{~s}, 1 \mathrm{H}), 7.56(\mathrm{~s}, 1 \mathrm{H})$, $7.51(\mathrm{dd}, J=8.8,2.5 \mathrm{~Hz}, 1 \mathrm{H}), 7.45(\mathrm{~d}, J=2.4 \mathrm{~Hz}, 1 \mathrm{H}), 7.30(\mathrm{~d}, J=8.9 \mathrm{~Hz}, 1 \mathrm{H}), 5.47(\mathrm{~s}, 2 \mathrm{H}), 5.39(\mathrm{~s}, 1 \mathrm{H})$, $4.95(\mathrm{~d}, J=12.7 \mathrm{~Hz}, 1 \mathrm{H}), 4.93(\mathrm{~d}, J=3.6 \mathrm{~Hz}, 1 \mathrm{H}), 4.69(\mathrm{~d}, J=12.6 \mathrm{~Hz}, 1 \mathrm{H}), 2.68-2.62(\mathrm{~m}, 1 \mathrm{H}), 2.35$ $(\mathrm{td}, J=14.0,4.0 \mathrm{~Hz}, 1 \mathrm{H}), 2.03-1.99(\mathrm{~m}, 1 \mathrm{H}), 1.87-1.82(\mathrm{~m}, 1 \mathrm{H}), 1.75-1.71(\mathrm{~m}, 2 \mathrm{H}), 1.62-1.59(\mathrm{~m}, 1 \mathrm{H})$, $1.48-1.43(\mathrm{~m}, 2 \mathrm{H}), 1.42(\mathrm{~s}, 3 \mathrm{H}), 1.31-1.19(\mathrm{~m}, 3 \mathrm{H}), 0.92(\mathrm{~d}, J=6.3 \mathrm{~Hz}, 3 \mathrm{H}), 0.89(\mathrm{~d}, J=7.4 \mathrm{~Hz}, 3 \mathrm{H}) ;{ }^{13} \mathrm{C}$ $\operatorname{NMR}\left(150 \mathrm{MHz}, \mathrm{CDCl}_{3}\right) \delta$ (ppm): 158.96, 150.95, 144.73, 139.79, 131.37, 129.27, 126.46, 123.19, 122.67, 118.51, 117.16, 103.12, 100.86, 86.95, 80.06, 76.21, 75.99, 75.78, 60.75, 51.47, 47.84, 43.33, 36.36, 35.36, 33.52, 29.79, 25.10, 23.62, 23.42, 19.30, 12.00; ESI-HRMS [M + Na] ${ }^{+}:(m / z)$ Calcd. for $\mathrm{C}_{28} \mathrm{H}_{32} \mathrm{ClN}_{3} \mathrm{O}_{7} \mathrm{Na}$ 580.1826. Found: 580.1788 .

6,8-dichloro-3-((4-((10S)-dihydroartemisininoxy)methyl-1H-1,2,3-triazol-1-yl)-methyl)-2H-1-chromen-2-one (1d) White solid; m.p. 113-115 ${ }^{\circ} \mathrm{C}$; yield 60\%; ${ }^{1} \mathrm{H}$ NMR (600 MHz, $\left.\mathrm{CDCl}_{3}\right) \delta$ (ppm): 7.75 (s, $\left.1 \mathrm{H}\right), 7.61$ $(\mathrm{d}, J=2.3 \mathrm{~Hz}, 1 \mathrm{H}), 7.55(\mathrm{~s}, 1 \mathrm{H}), 7.37(\mathrm{~d}, J=2.4 \mathrm{~Hz}, 1 \mathrm{H}), 5.48(\mathrm{~s}, 2 \mathrm{H}), 5.37(\mathrm{~s}, 1 \mathrm{H}), 4.96-4.92(\mathrm{~m}, 2 \mathrm{H})$, $4.70(\mathrm{~d}, J=12.7 \mathrm{~Hz}, 1 \mathrm{H}), 2.69-2.62(\mathrm{~m}, 1 \mathrm{H}), 2.38-2.33(\mathrm{~m}, 1 \mathrm{H}), 2.04-1.99(\mathrm{~m}, 1 \mathrm{H}), 1.87-1.82(\mathrm{~m}, 1 \mathrm{H})$, 1.76-1.72 (m, 3H), 1.62-1.59 (m, 1H), $1.42(\mathrm{~s}, 3 \mathrm{H}), 1.32-1.18(\mathrm{~m}, 4 \mathrm{H}), 0.92(\mathrm{~d}, J=6.3 \mathrm{~Hz}, 3 \mathrm{H}), 0.89$ (d, $J=7.3 \mathrm{~Hz}, 3 \mathrm{H}) ;{ }^{13} \mathrm{C} \mathrm{NMR}\left(150 \mathrm{MHz}, \mathrm{CDCl}_{3}\right) \delta(\mathrm{ppm}): 157.92,146.92,144.86,139.45,131.36,129.12$, 125.03, 124.04, 122.68, 121.71, 119.30, 103.13, 100.95, 86.94, 80.04, 76.20, 75.99, 75.78, 60.80, 51.44, 47.63, 43.31, 36.37, 35.35, 33.51, 29.79, 25.09, 23.61, 23.42, 19.28, 12.00; ESI-HRMS [M + Na] ${ }^{+}:(\mathrm{m} / z)$ Calcd. for $\mathrm{C}_{28} \mathrm{H}_{31} \mathrm{Cl}_{2} \mathrm{~N}_{3} \mathrm{O}_{7} \mathrm{Na}$ : 614.1437. Found: 614.1428 .

6,8-dibromo-3-((4-((10S)-dihydroartemisininoxy)methyl-1H-1,2,3-triazol-1-yl)-methyl)-2H-1-chromen-2-one (1e) White solid; m.p. 103-105 ${ }^{\circ} \mathrm{C}$; yield 61\%; ${ }^{1} \mathrm{H}$ NMR $\left(600 \mathrm{MHz}, \mathrm{CDCl}_{3}\right) \delta$ (ppm): $7.90(\mathrm{~d}, J=2.2$ $\mathrm{Hz}, 1 \mathrm{H}), 7.75(\mathrm{~s}, 1 \mathrm{H}), 7.56(\mathrm{~d}, J=2.2 \mathrm{~Hz}, 1 \mathrm{H}), 7.52(\mathrm{~s}, 1 \mathrm{H}), 5.48(\mathrm{~s}, 2 \mathrm{H}), 5.37(\mathrm{~s}, 1 \mathrm{H}), 4.96-4.92(\mathrm{~m}, 2 \mathrm{H})$, $4.70(\mathrm{~d}, J=12.7 \mathrm{~Hz}, 1 \mathrm{H}), 2.67-2.63(\mathrm{~m}, 1 \mathrm{H}), 2.38-2.33(\mathrm{~m}, 1 \mathrm{H}), 2.03-1.99(\mathrm{~m}, 1 \mathrm{H}), 1.87-1.82(\mathrm{~m}, 1 \mathrm{H})$, 
$1.76-1.72(\mathrm{~m}, 2 \mathrm{H}), 1.62-1.58(\mathrm{~m}, 4 \mathrm{H}), 1.42(\mathrm{~s}, 3 \mathrm{H}), 1.25-1.19(\mathrm{~m}, 2 \mathrm{H}), 0.92(\mathrm{~d}, J=6.3 \mathrm{~Hz}, 3 \mathrm{H}), 0.90(\mathrm{~d}$, $J=7.4 \mathrm{~Hz}, 3 \mathrm{H}) ;{ }^{13} \mathrm{C} \mathrm{NMR}\left(150 \mathrm{MHz}, \mathrm{CDCl}_{3}\right) \delta$ (ppm): 158.01, 148.45, 144.87, 139.36, 136.89, 128.75, 123.97, 122.67, 119.74, 116.48, 110.29, 103.13, 100.97, 86.95, 80.04, 76.20, 75.99, 75.78, 60.82, 51.45, 47.56, 43.31, 36.37, 35.35, 33.51, 29.79, 25.09, 23.62, 23.42, 19.30, 12.00; ESI-HRMS [M + Na] $]^{+}:(\mathrm{m} / \mathrm{z})$ Calcd. for $\mathrm{C}_{28} \mathrm{H}_{31} \mathrm{Br}_{2} \mathrm{~N}_{3} \mathrm{O}_{7} \mathrm{Na}$ : 702.0426. Found: 702.0421.

3-((4-(2-((10S)-dihydroartemisininoxy)ethyl)-1H-1,2,3-triazol-1-yl)-methyl)-2H-1-chromen-2-one (2a) White solid; m.p. $143-145^{\circ} \mathrm{C}$; yield $66 \%{ }^{1} \mathrm{H}$ NMR $\left(600 \mathrm{MHz}, \mathrm{CDCl}_{3}\right) \delta(\mathrm{ppm}): 7.65(\mathrm{~s}, 1 \mathrm{H}), 7.63(\mathrm{~s}, 1 \mathrm{H}), 7.56$ $(\mathrm{ddd}, J=8.7,7.3,1.6 \mathrm{~Hz}, 1 \mathrm{H}), 7.47(\mathrm{dd}, J=7.8,1.6 \mathrm{~Hz}, 1 \mathrm{H}), 7.35(\mathrm{~d}, J=8.4 \mathrm{~Hz}, 1 \mathrm{H}), 7.30(\mathrm{td}, J=7.5,1.1$ $\mathrm{Hz}, 1 \mathrm{H}), 5.44(\mathrm{~s}, 2 \mathrm{H}), 5.29(\mathrm{~d}, J=9.7 \mathrm{~Hz}, 1 \mathrm{H}), 4.78(\mathrm{~d}, J=3.6 \mathrm{~Hz}, 1 \mathrm{H}), 4.13-4.09(\mathrm{~m}, 1 \mathrm{H}), 3.69-3.65(\mathrm{~m}$, $1 \mathrm{H}), 3.07-2.97(\mathrm{~m}, 2 \mathrm{H}), 2.61-2.55(\mathrm{~m}, 1 \mathrm{H}), 2.33(\mathrm{td}, J=14.0,4.0 \mathrm{~Hz}, 1 \mathrm{H}), 2.01-1.97(\mathrm{~m}, 1 \mathrm{H}), 1.85-1.81$ $(\mathrm{m}, 1 \mathrm{H}), 1.71-1.67(\mathrm{~m}, 2 \mathrm{H}), 1.59-1.56(\mathrm{~m}, 1 \mathrm{H}), 1.41(\mathrm{~s}, 3 \mathrm{H}), 1.40-1.38(\mathrm{~m}, 1 \mathrm{H}), 1.28-1.16(\mathrm{~m}, 3 \mathrm{H}), 0.91$ $(\mathrm{d}, J=6.3 \mathrm{~Hz}, 3 \mathrm{H}), 0.89-0.83(\mathrm{~m}, 1 \mathrm{H}), 0.80(\mathrm{~d}, J=7.3 \mathrm{~Hz}, 3 \mathrm{H}) ;{ }^{13} \mathrm{C} \mathrm{NMR}\left(150 \mathrm{MHz}, \mathrm{CDCl}_{3}\right) \delta(\mathrm{ppm})$ : 159.65, 152.64, 144.77, 141.15, 131.43, 127.30, 123.90, 121.98, 121.78, 117.52, 115.70, 103.03, 100.92, 86.84, 80.02, 76.21, 76.00, 75.78, 66.18, 51.47, 47.86, 43.28, 36.34, 35.36, 33.55, 29.79, 25.57, 25.14, 23.62, 23.34, 19.33, 11.93; ESI-HRMS [M + Na] $]^{+}:(\mathrm{m} / \mathrm{z})$ Calcd. for $\mathrm{C}_{29} \mathrm{H}_{35} \mathrm{~N}_{3} \mathrm{O}_{7} \mathrm{Na}$ : 560.2373. Found: 560.2417.

6-bromo-3-((4-(2-((10S)-dihydroartemisininoxy)ethyl)-1H-1,2,3-triazol-1-yl)-methyl)-2H-1-chromen-2-one (2b) White solid; m.p. $138-140{ }^{\circ} \mathrm{C}$; yield 52\%; ${ }^{1} \mathrm{H} \mathrm{NMR}\left(600 \mathrm{MHz}, \mathrm{CDCl}_{3}\right) \delta(\mathrm{ppm}): 7.64(\mathrm{dd}, J=8.8,2.3 \mathrm{~Hz}$, $1 \mathrm{H}), 7.61(\mathrm{~d}, J=2.3 \mathrm{~Hz}, 1 \mathrm{H}), 7.60(\mathrm{~s}, 1 \mathrm{H}), 7.52(\mathrm{~s}, 1 \mathrm{H}), 7.23(\mathrm{~d}, J=8.8 \mathrm{~Hz}, 1 \mathrm{H}), 5.43(\mathrm{~s}, 2 \mathrm{H}), 5.28(\mathrm{~s}, 1 \mathrm{H})$, $4.79(\mathrm{~d}, J=3.5 \mathrm{~Hz}, 1 \mathrm{H}), 4.13-4.09(\mathrm{~m}, 1 \mathrm{H}), 3.70-3.66(\mathrm{~m}, 1 \mathrm{H}), 3.07-2.98(\mathrm{~m}, 2 \mathrm{H}), 2.62-2.57(\mathrm{~m}, 1 \mathrm{H}), 2.34$ $(\mathrm{td}, J=14.0,4.0 \mathrm{~Hz}, 1 \mathrm{H}), 2.01-1.98(\mathrm{~m}, 1 \mathrm{H}), 1.86-1.81(\mathrm{~m}, 1 \mathrm{H}), 1.71-1.67(\mathrm{~m}, 2 \mathrm{H}), 1.60-1.56(\mathrm{~m}, 1 \mathrm{H}), 1.42$ $(\mathrm{s}, 3 \mathrm{H}), 1.40-1.37(\mathrm{~m}, 1 \mathrm{H}), 1.27-1.17(\mathrm{~m}, 3 \mathrm{H}), 0.92(\mathrm{~d}, J=6.2 \mathrm{~Hz}, 3 \mathrm{H}), 0.89-0.85(\mathrm{~m}, 1 \mathrm{H}), 0.82(\mathrm{~d}, J=7.3$ $\mathrm{Hz}, 3 \mathrm{H}) ;{ }^{13} \mathrm{C} \mathrm{NMR}\left(150 \mathrm{MHz}, \mathrm{CDCl}_{3}\right) \delta$ (ppm): 158.90, 151.40, 144.86, 139.50, 134.15, 129.51, 123.31, 121.76, 118.99, 117.41, 116.51, 103.06, 100.92, 86.85, 80.00, 76.20, 75.99, 75.78, 66.18, 51.45, 47.72, 43.26, $36.37,35.35,33.55,29.78,25.56,25.14,23.63,23.35,19.32,11.95$; ESI-HRMS [M + Na] $]^{+}:(\mathrm{m} / z)$ Calcd. for $\mathrm{C}_{29} \mathrm{H}_{34} \mathrm{BrN}_{3} \mathrm{O}_{7} \mathrm{Na}$ : 638.1478. Found: 638.1508 .

6-chloro-3-((4-(2-((10S)-dihydroartemisininoxy)ethyl)-1H-1,2,3-triazol-1-yl)-methyl)-2H-1-chromen-2-one (2c) White solid; m.p. $138-140{ }^{\circ} \mathrm{C}$; yield $52 \%$; ${ }^{1} \mathrm{H}$ NMR $\left(600 \mathrm{MHz}, \mathrm{CDCl}_{3}\right) \delta(\mathrm{ppm}): 7.60(\mathrm{~s}, 1 \mathrm{H}), 7.53(\mathrm{~s}$, $1 \mathrm{H}), 7.50(\mathrm{dd}, J=8.8,2.5 \mathrm{~Hz}, 1 \mathrm{H}), 7.45(\mathrm{~d}, J=2.4 \mathrm{~Hz}, 1 \mathrm{H}), 7.29(\mathrm{~d}, J=8.8 \mathrm{~Hz}, 1 \mathrm{H}), 5.43(\mathrm{~d}, J=1.1$ $\mathrm{Hz}, 2 \mathrm{H}), 5.28(\mathrm{~s}, 1 \mathrm{H}), 4.79(\mathrm{~d}, J=3.6 \mathrm{~Hz}, 1 \mathrm{H}), 4.13-4.09(\mathrm{~m}, 1 \mathrm{H}), 3.70-3.66(\mathrm{~m}, 1 \mathrm{H}), 3.05-2.99(\mathrm{~m}, 2 \mathrm{H})$, 2.61-2.58 (m, 1H), 2.37-2.31 (m, 1H), 2.01-1.98 (m, 1H), 1.86-1.81 (m, 1H), 1.70-1.68 (m, 2H), 1.60-1.56 $(\mathrm{m}, 1 \mathrm{H}), 1.42(\mathrm{~s}, 3 \mathrm{H}), 1.41-1.36(\mathrm{~m}, 1 \mathrm{H}), 1.26-1.17(\mathrm{~m}, 3 \mathrm{H}), 0.92(\mathrm{~d}, J=6.2 \mathrm{~Hz}, 3 \mathrm{H}), 0.89-0.85(\mathrm{~m}, 1 \mathrm{H})$, $0.82(\mathrm{~d}, J=7.3 \mathrm{~Hz}, 3 \mathrm{H}) ;{ }^{13} \mathrm{C} \mathrm{NMR}\left(150 \mathrm{MHz}, \mathrm{CDCl}_{3}\right) \delta(\mathrm{ppm}): 158.97,150.93,144.87,139.62,131.34$, 129.25, 126.47, 123.35, 121.76, 118.51, 117.14, 103.06, 100.93, 86.85, 80.00, 76.20, 75.99, 75.78, 66.19, 51.45, $47.72,43.27,36.37,35.35,33.56,29.79,25.57,25.14,23.63,23.35,19.32,11.95 ;$ ESI-HRMS [M + Na] $]^{+}:(\mathrm{m} / \mathrm{z})$ Calcd. for $\mathrm{C}_{29} \mathrm{H}_{34} \mathrm{ClN}_{3} \mathrm{O}_{7} \mathrm{Na}$ : 594.1983. Found: 594.2002.

6,8-dichloro-3-((4-(2-((10S)-dihydroartemisininoxy)ethyl)-1H-1,2,3-triazol-1-yl)-methyl)-2H-1-chromen-2-one (2d) White solid; m.p. $101-103{ }^{\circ} \mathrm{C}$; yield $50 \% ;{ }^{1} \mathrm{H}$ NMR $\left(600 \mathrm{MHz}, \mathrm{CDCl}_{3}\right) \delta(\mathrm{ppm}): 7.60(\mathrm{~d}, J=2.2 \mathrm{~Hz}$, 2H), $7.52(\mathrm{~s}, 1 \mathrm{H}), 7.37(\mathrm{~d}, J=2.3 \mathrm{~Hz}, 1 \mathrm{H}), 5.45(\mathrm{~s}, 2 \mathrm{H}), 5.27(\mathrm{~s}, 1 \mathrm{H}), 4.79(\mathrm{~d}, J=3.5 \mathrm{~Hz}, 1 \mathrm{H}), 4.13-4.08(\mathrm{~m}$, $1 \mathrm{H}), 3.71-3.67(\mathrm{~m}, 1 \mathrm{H}), 3.04-3.01(\mathrm{~m}, 2 \mathrm{H}), 2.61-2.59(\mathrm{~m}, 1 \mathrm{H}), 2.34(\mathrm{td}, J=14.0,4.0 \mathrm{~Hz}, 1 \mathrm{H}), 2.02-1.98(\mathrm{~m}$, $1 \mathrm{H}), 1.85-1.82(\mathrm{~m}, 1 \mathrm{H}), 1.71-1.68(\mathrm{~m}, 2 \mathrm{H}), 1.60-1.58(\mathrm{~m}, 1 \mathrm{H}), 1.42(\mathrm{~s}, 3 \mathrm{H}), 1.41-1.36(\mathrm{~m}, 1 \mathrm{H}), 1.26-1.17$ $(\mathrm{m}, 3 \mathrm{H}), 0.92(\mathrm{~d}, J=6.1 \mathrm{~Hz}, 3 \mathrm{H}), 0.90-0.85(\mathrm{~m}, 1 \mathrm{H}), 0.82(\mathrm{~d}, J=7.3 \mathrm{~Hz}, 3 \mathrm{H}) ;{ }^{13} \mathrm{C}$ NMR $(150 \mathrm{MHz}$, $\mathrm{CDCl}_{3}$ ) $\delta$ (ppm): 157.93, 146.90, 144.92, 139.29, 131.34, 129.12, 125.04, 124.16, 121.82, 121.70, 119.30, 103.07, 100.94, 86.86, 79.99, 76.20, 75.99, 75.78, 66.17, 51.44, 47.57, 43.26, 36.39, 35.35, 33.55, 29.78, 25.53, 25.13, 23.63, 23.35, 19.32, 11.95; ESI-HRMS [M + Na] $]^{+}(\mathrm{m} / \mathrm{z})$ Calcd. for $\mathrm{C}_{29} \mathrm{H}_{33} \mathrm{Cl}_{2} \mathrm{~N}_{3} \mathrm{O}_{7} \mathrm{Na}$ : 628.1593 . Found: 628.1360 .

6,8-dibromo-3-((4-(2-((10S)-dihydroartemisininoxy)ethyl)-1H-1,2,3-triazol-1-yl)-methyl)-2H-1-chromen-2-one (2e) White solid; m.p. 93-95 ${ }^{\circ} \mathrm{C}$; yield 44\%; ${ }^{1} \mathrm{H}$ NMR $\left(600 \mathrm{MHz}, \mathrm{CDCl}_{3}\right) \delta(\mathrm{ppm}): 7.83(\mathrm{~d}, J=2.1 \mathrm{~Hz}$, $1 \mathrm{H}), 7.53(\mathrm{~s}, 1 \mathrm{H}), 7.49(\mathrm{~d}, J=2.2 \mathrm{~Hz}, 1 \mathrm{H}), 7.42(\mathrm{~s}, 1 \mathrm{H}), 5.38(\mathrm{~s}, 2 \mathrm{H}), 5.21(\mathrm{~s}, 1 \mathrm{H}), 4.73(\mathrm{~d}, J=3.4 \mathrm{~Hz}, 1 \mathrm{H})$, 
4.06-4.02 (m, 1H), 3.64-3.60 (m, 1H), 2.97-2.94 (m, 2H), 2.56-2.51 (m, 1H), 2.30-2.25 (m, 1H), 1.95-1.91 $(\mathrm{m}, 1 \mathrm{H}), 1.79-1.75(\mathrm{~m}, 1 \mathrm{H}), 1.64-1.60(\mathrm{~m}, 2 \mathrm{H}), 1.52(\mathrm{dd}, J=13.2,3.3 \mathrm{~Hz}, 1 \mathrm{H}), 1.35(\mathrm{~s}, 3 \mathrm{H}), 1.34-1.29(\mathrm{~m}$, $1 \mathrm{H}), 1.19-1.11(\mathrm{~m}, 3 \mathrm{H}), 0.85(\mathrm{~d}, J=6.1 \mathrm{~Hz}, 3 \mathrm{H}), 0.83-0.78(\mathrm{~m}, 1 \mathrm{H}), 0.75(\mathrm{~d}, J=7.4 \mathrm{~Hz}, 3 \mathrm{H}) ;{ }^{13} \mathrm{C} \mathrm{NMR}$ $\left(150 \mathrm{MHz}, \mathrm{CDCl}_{3}\right) \delta$ (ppm): 158.01, 148.41, 144.96, 139.16, 136.85, 128.75, 124.12, 121.77, 119.74, 116.47, 110.26, 103.07, 100.93, 86.86, 80.00, 76.21, 76.00, 75.79, 66.19, 51.44, 47.48, 43.26, 36.39, 35.35, 33.55, 29.78, 25.56, 25.13, 23.63, 23.35, 19.33, 11.96; ESI-HRMS [M + Na] ${ }^{+}:(\mathrm{m} / \mathrm{z})$ Calcd. for $\mathrm{C}_{29} \mathrm{H}_{33} \mathrm{Br}_{2} \mathrm{~N}_{3} \mathrm{O}_{7} \mathrm{Na}$ : 716.0583. Found: 716.0381.

\subsubsection{General Procedure for the Synthesis of Compounds $3 \mathbf{f}-\mathbf{3 i}$ and $\mathbf{4 f}-\mathbf{4 i}$}

Substituted coumarin (f-i) $(10 \mathrm{mmol})$, substituted DHA (III or IV) $(10 \mathrm{mmol})$ and triethylamine (10 mmol) were dissolved in $20 \mathrm{~mL} \mathrm{CH}_{2} \mathrm{Cl}_{2}$. In addition, $\mathrm{CuI}(100 \mathrm{mg})$ was added and the reaction mixture was stirred at room temperature for $8 \mathrm{~h}$ under the protection of nitrogen. The mixture was filtered, washed with water, dried over $\mathrm{Na}_{2} \mathrm{SO}_{4}$ and evaporated to dryness. The crude product was purified through column chromatography.

7-hydroxy-4-((4-((10S)-dihydroartemisininoxy)methyl-1H-1,2,3-triazol-1-yl)-methyl)-2H-1-chromen-2-one (3f) White solid; m.p. $165-167{ }^{\circ} \mathrm{C}$; yield $54 \% ;{ }^{1} \mathrm{H}$ NMR $\left(600 \mathrm{MHz}, \mathrm{CDCl}_{3}\right) \delta(\mathrm{ppm}): 9.61(\mathrm{~s}, 1 \mathrm{H}), 7.68(\mathrm{~d}$, $J=8.8 \mathrm{~Hz}, 1 \mathrm{H}), 7.67(\mathrm{~s}, 1 \mathrm{H}), 6.99(\mathrm{dd}, J=8.8,2.4 \mathrm{~Hz}, 1 \mathrm{H}), 6.85(\mathrm{~d}, J=2.4 \mathrm{~Hz}, 1 \mathrm{H}), 6.15(\mathrm{~s}, 1 \mathrm{H}), 5.76(\mathrm{~d}, J$ $=15.4 \mathrm{~Hz}, 1 \mathrm{H}), 5.57(\mathrm{~d}, J=15.3 \mathrm{~Hz}, 1 \mathrm{H}), 5.20(\mathrm{~s}, 1 \mathrm{H}), 4.87(\mathrm{~d}, J=1.9 \mathrm{~Hz}, 1 \mathrm{H}), 4.86(\mathrm{~d}, J=7.4 \mathrm{~Hz}, 1 \mathrm{H})$, $4.68(\mathrm{~d}, J=12.9 \mathrm{~Hz}, 1 \mathrm{H}), 2.62-2.60(\mathrm{~m}, 1 \mathrm{H}), 2.34-2.29(\mathrm{~m}, 1 \mathrm{H}), 2.02-1.98(\mathrm{~m}, 1 \mathrm{H}), 1.82-1.78(\mathrm{~m}, 1 \mathrm{H})$, $1.66-1.61(\mathrm{~m}, 3 \mathrm{H}), 1.61-1.57(\mathrm{~m}, 1 \mathrm{H}), 1.45-1.42(\mathrm{~m}, 1 \mathrm{H}), 1.40(\mathrm{~s}, 3 \mathrm{H}), 1.20-1.08(\mathrm{~m}, 3 \mathrm{H}), 0.84(\mathrm{~d}, J=7.4$ $\mathrm{Hz}, 3 \mathrm{H}), 0.82(\mathrm{~d}, J=6.1 \mathrm{~Hz}, 3 \mathrm{H}) ;{ }^{13} \mathrm{C}$ NMR $\left(150 \mathrm{MHz}, \mathrm{CDCl}_{3}\right) \delta(\mathrm{ppm}): 160.88,159.75,154.96,146.45$, 145.19, 124.19, 122.29, 112.78, 111.57, 108.80, 103.21, 103.04, 101.40, 86.91, 79.92, 76.20, 75.99, 75.78, 60.44, 51.32, 50.16, 43.18, 36.28, 35.26, 33.42, 29.74, 25.00, 23.53, 23.32, 19.26, 11.89; ESI-HRMS [M + Na] ${ }^{+}:(\mathrm{m} / \mathrm{z})$ Calcd. for $\mathrm{C}_{28} \mathrm{H}_{33} \mathrm{~N}_{3} \mathrm{O}_{8} \mathrm{Na}$ : 562.2165. Found: 562.2172.

5,7-dimethyl-4-((4-((10S)-dihydroartemisininoxy)methyl-1H-1,2,3-triazol-1-yl)-methyl)-2H-1-chromen-2-one (3g) White solid; m.p. 133 135 ${ }^{\circ} \mathrm{C}$; yield 57\%; ${ }^{1} \mathrm{H}$ NMR $\left(600 \mathrm{MHz}, \mathrm{CDCl}_{3}\right) \delta(\mathrm{ppm}): 7.56(\mathrm{~s}, 1 \mathrm{H}), 7.07(\mathrm{~s}$, $1 \mathrm{H}), 6.95(\mathrm{~s}, 1 \mathrm{H}), 5.90(\mathrm{~d}, J=17.0 \mathrm{~Hz}, 1 \mathrm{H}), 5.86(\mathrm{~d}, J=17.0 \mathrm{~Hz}, 1 \mathrm{H}), 5.51(\mathrm{~s}, 1 \mathrm{H}), 5.41(\mathrm{~s}, 1 \mathrm{H}), 4.98(\mathrm{~d}$, $J=12.8 \mathrm{~Hz}, 1 \mathrm{H}), 4.93(\mathrm{~d}, J=3.5 \mathrm{~Hz}, 1 \mathrm{H}), 4.73(\mathrm{~d}, J=12.8 \mathrm{~Hz}, 1 \mathrm{H}), 2.68(\mathrm{~s}, 3 \mathrm{H}), 2.40(\mathrm{~s}, 3 \mathrm{H}), 2.35(\mathrm{dd}$, $J=14.0,4.0 \mathrm{~Hz}, 1 \mathrm{H}), 2.05-2.01(\mathrm{~m}, 1 \mathrm{H}), 1.88-1.85(\mathrm{~m}, 1 \mathrm{H}), 1.75-1.70(\mathrm{~m}, 2 \mathrm{H}), 1.60(\mathrm{dd}, J=13.2,3.4 \mathrm{~Hz}$, $1 \mathrm{H}), 1.48-1.46(\mathrm{~m}, 1 \mathrm{H}), 1.43(\mathrm{~s}, 3 \mathrm{H}), 1.32-1.20(\mathrm{~m}, 5 \mathrm{H}), 0.93(\mathrm{~d}, J=6.3 \mathrm{~Hz}, 3 \mathrm{H}), 0.89(\mathrm{~d}, J=7.4 \mathrm{~Hz}$, $3 \mathrm{H}) ;{ }^{13} \mathrm{C} \mathrm{NMR}\left(150 \mathrm{MHz}, \mathrm{CDCl}_{3}\right) \delta$ (ppm): 158.67, 154.26, 149.33, 145.35, 142.10, 133.93, 129.26, 122.10, $115.63,113.36,112.80,103.16,100.93,86.98,80.05,76.21,76.00,75.79,60.80,52.05,51.48,43.31,36.34$, 35.36, 33.50, 29.78, 25.11, 23.61, 23.44, 23.28, 20.24, 19.31, 12.01; ESI-HRMS [M + Na] ${ }^{+}:(\mathrm{m} / \mathrm{z})$ Calcd. for $\mathrm{C}_{30} \mathrm{H}_{37} \mathrm{~N}_{3} \mathrm{O}_{7} \mathrm{Na}$ : 574.2539. Found: 574.2553.

7-methyl-4-((4-((10S)-dihydroartemisininoxy)methyl-1H-1,2,3-triazol-1-yl)-methyl)-2H-1-chromen-2-one (3h) White solid; m.p. $107-109{ }^{\circ} \mathrm{C}$; yield 50\%; ${ }^{1} \mathrm{H}$ NMR $\left(600 \mathrm{MHz}, \mathrm{CDCl}_{3}\right) \delta(\mathrm{ppm}): 7.58(\mathrm{~s}, 1 \mathrm{H}), 7.50(\mathrm{~d}$, $J=8.1 \mathrm{~Hz}, 1 \mathrm{H}), 7.19(\mathrm{~s}, 1 \mathrm{H}), 7.11(\mathrm{~d}, J=8.1 \mathrm{~Hz}, 1 \mathrm{H}), 6.01(\mathrm{~s}, 1 \mathrm{H}), 5.74(\mathrm{~d}, J=16.3 \mathrm{~Hz}, 1 \mathrm{H}), 5.64(\mathrm{~d}$, $J=16.0 \mathrm{~Hz}, 1 \mathrm{H}), 5.30(\mathrm{~s}, 1 \mathrm{H}), 4.92-4.88(\mathrm{~m}, 2 \mathrm{H}), 4.72(\mathrm{~d}, J=12.9 \mathrm{~Hz}, 1 \mathrm{H}), 2.65-2.61(\mathrm{~m}, 1 \mathrm{H}), 2.45(\mathrm{~s}$, $3 \mathrm{H}), 2.34(\mathrm{td}, J=14.0,4.0 \mathrm{~Hz}, 1 \mathrm{H}), 2.04-2.00(\mathrm{~m}, 1 \mathrm{H}), 1.86-1.81(\mathrm{~m}, 1 \mathrm{H}), 1.71-1.66(\mathrm{~m}, 2 \mathrm{H}), 1.58-1.55$ $(\mathrm{m}, 1 \mathrm{H}), 1.42(\mathrm{~s}, 3 \mathrm{H}), 1.26-1.18(\mathrm{~m}, 5 \mathrm{H}), 0.91(\mathrm{~d}, J=5.7 \mathrm{~Hz}, 3 \mathrm{H}), 0.86(\mathrm{~d}, J=7.3 \mathrm{~Hz}, 3 \mathrm{H}) ;{ }^{13} \mathrm{C}$ NMR $\left(150 \mathrm{MHz}, \mathrm{CDCl}_{3}\right) \delta$ (ppm): 159.01, 152.86, 146.75, 145.42, 143.16, 125.03, 122.23, 121.95, 116.71, 113.56, $113.41,103.15,101.10,86.93,80.00,76.21,75.99,75.78,60.90,51.41,49.29,43.27,36.34,35.31,33.47,29.77$, 25.06, 23.58, 23.38, 20.70, 19.30, 11.96; ESI-HRMS [M + Na] ${ }^{+}:(\mathrm{m} / \mathrm{z})$ Calcd. for $\mathrm{C}_{29} \mathrm{H}_{35} \mathrm{~N}_{3} \mathrm{O}_{7} \mathrm{Na}$ : 560.2373. Found: 560.2375 .

6-methyl-4-((4-((10S)-dihydroartemisininoxy)methyl-1H-1,2,3-triazol-1-yl)-methyl)-2H-1-chromen-2-one (3i) White solid; m.p. $88-90{ }^{\circ} \mathrm{C}$; yield $60 \%$; ${ }^{1} \mathrm{H}$ NMR $\left(600 \mathrm{MHz}, \mathrm{CDCl}_{3}\right) \delta(\mathrm{ppm}): 7.58(\mathrm{~s}, 1 \mathrm{H}), 7.39(\mathrm{~d}$, $J=8.8 \mathrm{~Hz}, 2 \mathrm{H}), 7.28(\mathrm{~d}, J=8.3 \mathrm{~Hz}, 1 \mathrm{H}), 6.01(\mathrm{~s}, 1 \mathrm{H}), 5.75(\mathrm{~d}, J=16.3 \mathrm{~Hz}, 1 \mathrm{H}), 5.66(\mathrm{~d}, J=16.3 \mathrm{~Hz}, 1 \mathrm{H})$, $5.32(\mathrm{~s}, 1 \mathrm{H}), 4.92(\mathrm{~d}, J=12.8 \mathrm{~Hz}, 1 \mathrm{H}), 4.90(\mathrm{~d}, J=3.5 \mathrm{~Hz}, 1 \mathrm{H}), 4.73(\mathrm{~d}, J=12.8 \mathrm{~Hz}, 1 \mathrm{H}), 2.67-2.60(\mathrm{~m}$, 
$1 \mathrm{H}), 2.41(\mathrm{~s}, 3 \mathrm{H}), 2.34(\mathrm{td}, J=14.0,4.0 \mathrm{~Hz}, 1 \mathrm{H}), 2.04-1.99(\mathrm{~m}, 1 \mathrm{H}), 1.86-1.81(\mathrm{~m}, 1 \mathrm{H}), 1.72-1.68(\mathrm{~m}, 2 \mathrm{H})$, $1.57(\mathrm{dd}, J=13.2,3.1 \mathrm{~Hz}, 1 \mathrm{H}), 1.42(\mathrm{~s}, 3 \mathrm{H}), 1.26-1.19(\mathrm{~m}, 5 \mathrm{H}), 0.91(\mathrm{~d}, J=5.7 \mathrm{~Hz}, 3 \mathrm{H}), 0.86(\mathrm{~d}, J=7.3$ $\mathrm{Hz}, 3 \mathrm{H}) ;{ }^{13} \mathrm{C}$ NMR $\left(150 \mathrm{MHz}, \mathrm{CDCl}_{3}\right) \delta$ (ppm): 158.91, 150.87, 146.72, 145.41, 133.69, 132.71, 122.26, $121.95,116.32,115.68,114.29,103.15,101.05,86.94,80.00,76.21,76.00,75.78,60.86,51.42,49.17,43.27$, $36.34,35.31,33.47,29.76,25.07,23.59,23.39,20.01,19.30,11.96$; ESI-HRMS [M + Na] ${ }^{+}:(\mathrm{m} / \mathrm{z})$ Calcd. for $\mathrm{C}_{29} \mathrm{H}_{35} \mathrm{~N}_{3} \mathrm{O}_{7} \mathrm{Na}$ : 560.2373. Found: 560.2403.

7-hydroxy-4-((4-(2-((10S)-dihydroartemisininoxy)ethyl)-1H-1,2,3-triazol-1-yl)-methyl)-2H-1-chromen-2-one (4f) White solid; m.p. $121-123{ }^{\circ} \mathrm{C}$; yield $54 \% ;{ }^{1} \mathrm{H}$ NMR $\left(600 \mathrm{MHz}, \mathrm{CDCl}_{3}\right) \delta(\mathrm{ppm})$ : $9.98(\mathrm{~s}, 1 \mathrm{H}), 7.68(\mathrm{~d}$, $J=8.8 \mathrm{~Hz}, 1 \mathrm{H}), 7.49(\mathrm{~s}, 1 \mathrm{H}), 7.01(\mathrm{dd}, J=8.8,2.4 \mathrm{~Hz}, 1 \mathrm{H}), 6.85(\mathrm{~d}, J=2.4 \mathrm{~Hz}, 1 \mathrm{H}), 6.16(\mathrm{~s}, 1 \mathrm{H}), 5.68-5.59$ $(\mathrm{m}, 2 \mathrm{H}), 5.20(\mathrm{~s}, 1 \mathrm{H}), 4.71(\mathrm{~d}, J=3.5 \mathrm{~Hz}, 1 \mathrm{H}), 4.08-4.04(\mathrm{~m}, 1 \mathrm{H}), 3.67-3.63(\mathrm{~m}, 1 \mathrm{H}), 3.03-2.94(\mathrm{~m}, 2 \mathrm{H})$, 2.56-2.53 (m, 1H), $2.33(\mathrm{td}, J=14.1,4.0 \mathrm{~Hz}, 1 \mathrm{H}), 2.03-1.99(\mathrm{~m}, 1 \mathrm{H}), 1.86-1.82(\mathrm{~m}, 1 \mathrm{H}), 1.58-1.54(\mathrm{~m}, 2 \mathrm{H})$, $1.51-1.48(\mathrm{~m}, 1 \mathrm{H}), 1.40(\mathrm{~s}, 3 \mathrm{H}), 1.40-1.35(\mathrm{~m}, 2 \mathrm{H}), 1.27-1.25(\mathrm{~m}, 1 \mathrm{H}), 1.20-1.16(\mathrm{~m}, 2 \mathrm{H}), 0.88(\mathrm{~d}, J=5.6$ $\mathrm{Hz}, 3 \mathrm{H}), 0.68(\mathrm{~d}, J=7.3 \mathrm{~Hz}, 3 \mathrm{H}) ;{ }^{13} \mathrm{C}$ NMR $\left(150 \mathrm{MHz}, \mathrm{CDCl}_{3}\right) \delta$ (ppm): 161.02, 159.72, 155.05, 146.56, 145.44, 124.28, 121.23, 112.79, 111.51, 108.74, 103.16, 103.05, 100.88, 86.87, 79.91, 76.20, 75.99, 75.78, 65.75, $51.37,50.15,43.11,36.37,35.30,33.45,29.66,25.24,25.09,23.62,23.29,19.29,11.73$; ESI-HRMS [M + $\mathrm{Na}]^{+}:(m / z)$ Calcd. for $\mathrm{C}_{29} \mathrm{H}_{35} \mathrm{~N}_{3} \mathrm{O}_{8} \mathrm{Na}$ : 576.2322. Found: 576.2352.

5,7-dimethyl-4-((4-(2-((10S)-dihydroartemisininoxy)ethyl)-1H-1,2,3-triazol-1-yl)-methyl)-2H-1-chromen-2-one (4g) White solid; m.p. $135-137{ }^{\circ} \mathrm{C}$; yield 52\%; ${ }^{1} \mathrm{H}$ NMR $\left(600 \mathrm{MHz}, \mathrm{CDCl}_{3}\right) \delta$ (ppm): $7.41(\mathrm{~s}, 1 \mathrm{H}), 7.06$ $(\mathrm{s}, 1 \mathrm{H}), 6.94(\mathrm{~s}, 1 \mathrm{H}), 5.84(\mathrm{~s}, 2 \mathrm{H}), 5.54(\mathrm{~s}, 1 \mathrm{H}), 5.28(\mathrm{~s}, 1 \mathrm{H}), 4.80(\mathrm{~d}, J=3.4 \mathrm{~Hz}, 1 \mathrm{H}), 4.15-4.10(\mathrm{~m}, 1 \mathrm{H})$, 3.73-3.69 (m, 1H), 3.11-3.00 (m, 2H), $2.66(\mathrm{~s}, 3 \mathrm{H}), 2.61-2.58(\mathrm{~m}, 1 \mathrm{H}), 2.40(\mathrm{~s}, 3 \mathrm{H}), 2.35(\mathrm{td}, J=14.1,4.0$ $\mathrm{Hz}, 1 \mathrm{H}), 2.03-1.99(\mathrm{~m}, 1 \mathrm{H}), 1.89-1.84(\mathrm{~m}, 1 \mathrm{H}), 1.70-1.63(\mathrm{~m}, 2 \mathrm{H}), 1.59-1.55(\mathrm{~m}, 1 \mathrm{H}), 1.49-1.43(\mathrm{~m}, 1 \mathrm{H})$, $1.42(\mathrm{~s}, 3 \mathrm{H}), 1.29-1.18(\mathrm{~m}, 3 \mathrm{H}), 0.93(\mathrm{~d}, J=6.3 \mathrm{~Hz}, 3 \mathrm{H}), 0.87(\mathrm{dd}, J=12.4,4.6 \mathrm{~Hz}, 1 \mathrm{H}), 0.80(\mathrm{~d}, J=7.3 \mathrm{~Hz}$, $3 \mathrm{H}) ;{ }^{13} \mathrm{C} \mathrm{NMR}\left(150 \mathrm{MHz}, \mathrm{CDCl}_{3}\right) \delta$ (ppm): 158.63, 154.30, 149.34, 145.42, 142.09, 133.98, 129.26, 121.15, 115.62, 113.33, 112.98, 103.07, 100.86, 86.87, 80.00, 76.21, 76.00, 75.79, 65.93, 52.03, 51.47, 43.25, 36.36, $35.37,33.55,29.76,25.58,25.15,23.66,23.32,23.21,20.24,19.35,11.98$; ESI-HRMS $[\mathrm{M}+\mathrm{Na}]^{+}:(\mathrm{m} / z)$ Calcd. for $\mathrm{C}_{31} \mathrm{H}_{39} \mathrm{~N}_{3} \mathrm{O}_{7} \mathrm{Na}$ : 588.2686. Found: 588.2680.

7-methyl-4-((4-(2-((10S)-dihydroartemisininoxy)ethyl)-1H-1,2,3-triazol-1-yl)-methyl)-2H-1-chromen-2-one (4h) White solid; m.p. $100-102{ }^{\circ} \mathrm{C}$; yield 53\%; ${ }^{1} \mathrm{H}$ NMR $\left(600 \mathrm{MHz}, \mathrm{CDCl}_{3}\right) \delta(\mathrm{ppm}): 7.48(\mathrm{~d}, J=8.1 \mathrm{~Hz}$, $1 \mathrm{H}), 7.40(\mathrm{~s}, 1 \mathrm{H}), 7.18(\mathrm{~s}, 1 \mathrm{H}), 7.11(\mathrm{~d}, J=8.2 \mathrm{~Hz}, 1 \mathrm{H}), 6.00(\mathrm{~s}, 1 \mathrm{H}), 5.68-5.62(\mathrm{~m}, 2 \mathrm{H}), 5.29(\mathrm{~d}, J=12.6 \mathrm{~Hz}$, $1 \mathrm{H}), 4.76(\mathrm{~d}, J=3.5 \mathrm{~Hz}, 1 \mathrm{H}), 4.11-4.08(\mathrm{~m}, 1 \mathrm{H}), 3.69-3.65(\mathrm{~m}, 1 \mathrm{H}), 3.06-2.96(\mathrm{~m}, 2 \mathrm{H}), 2.60-2.54(\mathrm{~m}, 1 \mathrm{H})$, $2.45(\mathrm{~s}, 3 \mathrm{H}), 2.34(\mathrm{td}, J=14.0,4.0 \mathrm{~Hz}, 1 \mathrm{H}), 2.05-1.99(\mathrm{~m}, 1 \mathrm{H}), 1.88-1.83(\mathrm{~m}, 1 \mathrm{H}), 1.66-1.63(\mathrm{~m}, 2 \mathrm{H})$, $1.60-1.58(\mathrm{~m}, 1 \mathrm{H}), 1.56-1.53(\mathrm{~m}, 1 \mathrm{H}), 1.41(\mathrm{~s}, 3 \mathrm{H}), 1.27-1.17(\mathrm{~m}, 3 \mathrm{H}), 0.93(\mathrm{~d}, J=6.1 \mathrm{~Hz}, 3 \mathrm{H}), 0.89-0.84$ $(\mathrm{m}, 1 \mathrm{H}), 0.74(\mathrm{~d}, J=7.3 \mathrm{~Hz}, 3 \mathrm{H}) ;{ }^{13} \mathrm{C}$ NMR $\left(150 \mathrm{MHz}, \mathrm{CDCl}_{3}\right) \delta(\mathrm{ppm}): 158.98,152.88,146.91,145.50$, 143.18, 125.06, 122.27, 120.82, 116.69, 113.56, 113.35, 103.08, 100.86, 86.86, 79.97, 76.21, 76.00, 75.78, 65.94, $51.44,49.21,43.21,36.36,35.35,33.54,29.72,25.55,25.14,23.65,23.31,20.69,19.34,11.86$; ESI-HRMS [M $+\mathrm{Na}]^{+}:(m / z)$ Calcd. for $\mathrm{C}_{30} \mathrm{H}_{37} \mathrm{~N}_{3} \mathrm{O}_{7} \mathrm{Na}$ : 574.2529. Found: 574.2567.

6-methyl-4-((4-(2-((10S)-dihydroartemisininoxy)ethyl)-1H-1,2,3-triazol-1-yl)-methyl)-2H-1-chromen-2-one (4i) White solid; m.p. $100-102{ }^{\circ} \mathrm{C}$; yield $43 \%$; ${ }^{1} \mathrm{H}$ NMR $\left(600 \mathrm{MHz}, \mathrm{CDCl}_{3}\right) \delta(\mathrm{ppm}): 7.40(\mathrm{~s}, 1 \mathrm{H}), 7.40(\mathrm{~s}, 1 \mathrm{H})$, $7.38(\mathrm{~d}, J=1.9 \mathrm{~Hz}, 1 \mathrm{H}), 7.28(\mathrm{~d}, J=8.3 \mathrm{~Hz}, 1 \mathrm{H}), 6.00(\mathrm{~d}, J=1.2 \mathrm{~Hz}, 1 \mathrm{H}), 5.67(\mathrm{~s}, 2 \mathrm{H}), 5.29(\mathrm{~s}, 1 \mathrm{H}), 4.77$ $(\mathrm{d}, J=3.4 \mathrm{~Hz}, 1 \mathrm{H}), 4.13-4.09(\mathrm{~m}, 1 \mathrm{H}), 3.71-3.67(\mathrm{~m}, 1 \mathrm{H}), 3.05-2.99(\mathrm{~m}, 2 \mathrm{H}), 2.61-2.56(\mathrm{~m}, 1 \mathrm{H}), 2.41(\mathrm{~s}$, $3 \mathrm{H}), 2.36-2.32(\mathrm{~m}, 1 \mathrm{H}), 2.03-2.00(\mathrm{~m}, 1 \mathrm{H}), 1.88-1.84(\mathrm{~m}, 1 \mathrm{H}), 1.66(\mathrm{dd}, J=13.7,3.5 \mathrm{~Hz}, 1 \mathrm{H}), 1.61(\mathrm{~d}$, $J=4.2 \mathrm{~Hz}, 1 \mathrm{H}), 1.58-1.53(\mathrm{~m}, 2 \mathrm{H}), 1.42(\mathrm{~s}, 3 \mathrm{H}), 1.24-1.16(\mathrm{~m}, 3 \mathrm{H}), 0.93(\mathrm{~d}, J=6.2 \mathrm{~Hz}, 3 \mathrm{H}), 0.88-0.85$ $(\mathrm{m}, 1 \mathrm{H}), 0.75$ (d, $J=7.3 \mathrm{~Hz}, 3 \mathrm{H}) ;{ }^{13} \mathrm{C} \mathrm{NMR}\left(150 \mathrm{MHz}, \mathrm{CDCl}_{3}\right) \delta$ (ppm): 158.88, 150.89, 146.89, 145.51, 133.70, 132.73, 122.29, 120.86, 116.31, 115.69, 114.22, 103.09, 100.87, 86.86, 79.98, 76.20, 75.99, 75.78, 65.94, $51.45,49.06,43.22,36.37,35.35,33.54,29.73,25.57,25.14,23.65,23.31,20.03,19.34,11.86$; ESI-HRMS [M $+\mathrm{Na}]^{+}:(m / z)$ Calcd. for $\mathrm{C}_{30} \mathrm{H}_{37} \mathrm{~N}_{3} \mathrm{O}_{7} \mathrm{Na}$ : 574.2529. Found: 574.2558. 


\subsubsection{General Procedure for the Synthesis of Compounds $\mathbf{5 j}, \mathbf{5 1 - 5 0}$, and $\mathbf{6 j - 6} \mathbf{p}$}

Substituted coumarin (j-p) $(10 \mathrm{mmol})$, substituted DHA (I or II) $(10 \mathrm{mmol})$ and triethylamine (10 mmol) were dissolved in $20 \mathrm{~mL} \mathrm{CH}_{2} \mathrm{Cl}_{2}$. In addition, $\mathrm{CuI}(100 \mathrm{mg})$ was added and the reaction mixture was stirred at room temperature for $8 \mathrm{~h}$ under the protection of nitrogen. The mixture was filtered, washed with water, dried over $\mathrm{Na}_{2} \mathrm{SO}_{4}$ and evaporated to dryness. The crude product was purified through column chromatography.

4-((4-(2-((10S)-dihydroartemisininoxy)ethyl)-1H-1,2,3-triazol-1-yl)-methoxy)-2H-1-chromen-2-one (5j) White solid; m.p. 91-93 ${ }^{\circ} \mathrm{C}$; yield 51\%; ${ }^{1} \mathrm{H}$ NMR $\left(600 \mathrm{MHz}, \mathrm{CDCl}_{3}\right) \delta(\mathrm{ppm}):$ 7.79-7.75 (m, 2H), $7.55(\mathrm{ddd}$, $J=8.7,7.3,1.6 \mathrm{~Hz}, 1 \mathrm{H}), 7.33(\mathrm{~d}, J=8.3 \mathrm{~Hz}, 1 \mathrm{H}), 7.25-7.22(\mathrm{~m}, 1 \mathrm{H}), 5.87(\mathrm{~s}, 1 \mathrm{H}), 5.34(\mathrm{~d}, J=2.7 \mathrm{~Hz}, 2 \mathrm{H})$, $5.16(\mathrm{~s}, 1 \mathrm{H}), 4.77(\mathrm{~d}, J=3.6 \mathrm{~Hz}, 1 \mathrm{H}), 4.72-4.68(\mathrm{~m}, 1 \mathrm{H}), 4.58-4.54(\mathrm{~m}, 1 \mathrm{H}), 4.32-4.29(\mathrm{~m}, 1 \mathrm{H}), 3.87-3.83$ $(\mathrm{m}, 1 \mathrm{H}), 2.63-2.60(\mathrm{~m}, 1 \mathrm{H}), 2.33(\mathrm{td}, J=14.0,4.0 \mathrm{~Hz}, 1 \mathrm{H}), 2.01-1.97(\mathrm{~m}, 1 \mathrm{H}), 1.87-1.81(\mathrm{~m}, 1 \mathrm{H}), 1.68-1.64$ $(\mathrm{m}, 1 \mathrm{H}), 1.58-1.55(\mathrm{~m}, 1 \mathrm{H}), 1.53-1.51(\mathrm{~m}, 1 \mathrm{H}), 1.41(\mathrm{~s}, 3 \mathrm{H}), 1.38(\mathrm{~d}, J=11.2 \mathrm{~Hz}, 1 \mathrm{H}), 1.26-1.18(\mathrm{~m}, 3 \mathrm{H})$, $0.91(\mathrm{~d}, J=5.9 \mathrm{~Hz}, 3 \mathrm{H}), 0.88-0.83(\mathrm{~m}, 1 \mathrm{H}), 0.78(\mathrm{~d}, J=7.4 \mathrm{~Hz}, 3 \mathrm{H}) ;{ }^{13} \mathrm{C} \mathrm{NMR}\left(150 \mathrm{MHz}, \mathrm{CDCl}_{3}\right) \delta(\mathrm{ppm})$ : 163.90, 161.51, 152.34, 140.45, 131.58, 122.86, 122.85, 122.04, 115.80, 114.40, 103.21, 101.15, 90.15, 86.86, 79.73, 76.20, 75.99, 75.78, 65.36, 61.67, 51.32, 49.57, 42.97, 36.35, 35.25, 33.41, 29.53, 25.06, 23.58, 23.32, 19.29, 11.80; ESI-HRMS [M + Na] ${ }^{+}:(m / z)$ Calcd. for $\mathrm{C}_{29} \mathrm{H}_{35} \mathrm{~N}_{3} \mathrm{O}_{8} \mathrm{Na}$ : 576.2322. Found: 576.2336.

5,7-dimethyl-4-((4-(2-((10S)-dihydroartemisininoxy)ethyl)-1H-1,2,3-triazol-1-yl)-methoxy)-2H-1-chromen2-one (51) White solid; m.p. 111-113 ${ }^{\circ} \mathrm{C}$; yield $49 \%$; ${ }^{1} \mathrm{H} \mathrm{NMR}\left(600 \mathrm{MHz}, \mathrm{CDCl}_{3}\right) \delta(\mathrm{ppm}): 7.74(\mathrm{~s}, 1 \mathrm{H})$, $6.98(\mathrm{~s}, 1 \mathrm{H}), 6.83(\mathrm{~s}, 1 \mathrm{H}), 5.75(\mathrm{~s}, 1 \mathrm{H}), 5.28(\mathrm{~s}, 2 \mathrm{H}), 5.14(\mathrm{~s}, 1 \mathrm{H}), 4.76(\mathrm{~d}, \mathrm{~J}=3.6 \mathrm{~Hz}, 1 \mathrm{H}), 4.70-4.66(\mathrm{~m}$, $1 \mathrm{H}), 4.58-4.54(\mathrm{~m}, 1 \mathrm{H}), 4.31-4.27(\mathrm{~m}, 1 \mathrm{H}), 3.87-3.84(\mathrm{~m}, 1 \mathrm{H}), 2.84(\mathrm{~s}, 1 \mathrm{H}), 2.61-2.59(\mathrm{~m}, 1 \mathrm{H}), 2.53(\mathrm{~s}$, $3 \mathrm{H}), 2.36(\mathrm{~s}, 3 \mathrm{H}), 2.35-2.30(\mathrm{~m}, 1 \mathrm{H}), 2.04-1.97(\mathrm{~m}, 2 \mathrm{H}), 1.87-1.82(\mathrm{~m}, 1 \mathrm{H}), 1.58-1.54(\mathrm{~m}, 1 \mathrm{H}), 1.52-1.50$ $(\mathrm{m}, 1 \mathrm{H}), 1.41(\mathrm{~s}, 3 \mathrm{H}), 1.25-1.17(\mathrm{~m}, 3 \mathrm{H}), 0.91(\mathrm{~d}, J=5.9 \mathrm{~Hz}, 3 \mathrm{H}), 0.88-0.85(\mathrm{~m}, 1 \mathrm{H}), 0.76(\mathrm{~d}, J=7.4 \mathrm{~Hz}$, $3 \mathrm{H}) ;{ }^{13} \mathrm{C}$ NMR $\left(150 \mathrm{MHz}, \mathrm{CDCl}_{3}\right) \delta$ (ppm): 166.97, 161.69, 153.91, 141.76, 140.42, 135.57, 127.92, 122.68, 114.43, 110.62, 103.21, 101.15, 89.15, 86.85, 79.74, 76.21, 76.00, 75.79, 65.38, 61.48, 51.33, 49.59, 42.97, $36.36,35.25,33.42,29.53,25.05,23.58,23.30,22.49,20.35,19.30,11.80$; ESI-HRMS [M + Na] ${ }^{+}:(m / z)$ Calcd. for $\mathrm{C}_{31} \mathrm{H}_{39} \mathrm{~N}_{3} \mathrm{O}_{8} \mathrm{Na}$ : 604.2635. Found: 604.2645 .

6,8-dimethyl-4-((4-(2-((10S)-dihydroartemisininoxy)ethyl)-1H-1,2,3-triazol-1-yl)-methoxy)-2H-1-chromen2-one (5m) White solid; m.p. 111-113 ${ }^{\circ} \mathrm{C}$; yield $49 \%$; ${ }^{1} \mathrm{H} \mathrm{NMR}\left(600 \mathrm{MHz}, \mathrm{CDCl}_{3}\right) \delta(\mathrm{ppm}): 7.77(\mathrm{~s}, 1 \mathrm{H})$, $7.39(\mathrm{~s}, 1 \mathrm{H}), 7.22(\mathrm{~s}, 1 \mathrm{H}), 5.83(\mathrm{~s}, 1 \mathrm{H}), 5.32(\mathrm{~d}, J=2.5 \mathrm{~Hz}, 2 \mathrm{H}), 5.17(\mathrm{~s}, 1 \mathrm{H}), 4.78(\mathrm{~d}, J=3.0 \mathrm{~Hz}, 1 \mathrm{H})$, $4.72-4.68(\mathrm{~m}, 1 \mathrm{H}), 4.59-4.55(\mathrm{~m}, 1 \mathrm{H}), 4.33-4.29(\mathrm{~m}, 1 \mathrm{H}), 3.87-3.83(\mathrm{~m}, 1 \mathrm{H}), 2.64-2.58(\mathrm{~m}, 1 \mathrm{H}), 2.41(\mathrm{~s}$, $3 \mathrm{H}), 2.37-2.33(\mathrm{~m}, 1 \mathrm{H}), 2.33(\mathrm{~s}, 3 \mathrm{H}), 2.02-1.98(\mathrm{~m}, 1 \mathrm{H}), 1.88-1.82(\mathrm{~m}, 1 \mathrm{H}), 1.68-1.63(\mathrm{~m}, 1 \mathrm{H}), 1.58-1.53$ $(\mathrm{m}, 1 \mathrm{H}), 1.53-1.48(\mathrm{~m}, 1 \mathrm{H}), 1.41(\mathrm{~s}, 3 \mathrm{H}), 1.41-1.38(\mathrm{~m}, 1 \mathrm{H}), 1.28-1.16(\mathrm{~m}, 3 \mathrm{H}), 0.91(\mathrm{~d}, J=5.9 \mathrm{~Hz}, 3 \mathrm{H})$, $0.88-0.84(\mathrm{~m}, 1 \mathrm{H}), 0.78(\mathrm{~d}, J=7.4 \mathrm{~Hz}, 3 \mathrm{H}) ;{ }^{13} \mathrm{C} \mathrm{NMR}\left(150 \mathrm{MHz}, \mathrm{CDCl}_{3}\right) \delta(\mathrm{ppm}): 165.31,162.94,149.91$, $141.55,134.98,133.03,125.90,123.94,120.25,114.82$, 104.23, 102.18, 90.77, 87.87, 80.76, 77.24, 77.02, 76.81, $66.39,62.54,52.35,50.58,44.01,37.37,36.28,34.44,30.57,26.07,24.61,24.35,20.82,20.31,15.65,12.84$; ESI-HRMS [M + Na] ${ }^{+}:(m / z)$ Calcd. for $\mathrm{C}_{31} \mathrm{H}_{39} \mathrm{~N}_{3} \mathrm{O}_{8} \mathrm{Na}$ : 604.2635. Found: 604.2639.

7,8-dimethyl-4-((4-(2-((10S)-dihydroartemisininoxy)ethyl)-1H-1,2,3-triazol-1-yl)-methoxy)-2H-1-chromen2-one (5n) White solid; m.p. 91-93 ${ }^{\circ} \mathrm{C}$; yield 51\%; ${ }^{1} \mathrm{H} \mathrm{NMR}\left(600 \mathrm{MHz}, \mathrm{CDCl}_{3}\right) \delta(\mathrm{ppm}): 7.76(\mathrm{~s}, 1 \mathrm{H})$, $7.50(\mathrm{~d}, J=8.1 \mathrm{~Hz}, 1 \mathrm{H}), 7.03(\mathrm{~d}, J=8.1 \mathrm{~Hz}, 1 \mathrm{H}), 5.79(\mathrm{~s}, 1 \mathrm{H}), 5.32(\mathrm{~d}, J=3.0 \mathrm{~Hz}, 2 \mathrm{H}), 5.15(\mathrm{~s}, 1 \mathrm{H}), 4.77(\mathrm{~d}$, $J=3.5 \mathrm{~Hz}, 1 \mathrm{H}), 4.71-4.67(\mathrm{~m}, 1 \mathrm{H}), 4.58-4.53(\mathrm{~m}, 1 \mathrm{H}), 4.33-4.27(\mathrm{~m}, 1 \mathrm{H}), 3.86-3.82(\mathrm{~m}, 1 \mathrm{H}), 2.63-2.58(\mathrm{~m}$, $1 \mathrm{H}), 2.37(\mathrm{~s}, 3 \mathrm{H}), 2.36(\mathrm{~s}, 3 \mathrm{H}), 2.34-2.30(\mathrm{~m}, 1 \mathrm{H}), 2.01-1.97(\mathrm{~m}, 1 \mathrm{H}), 1.86-1.81(\mathrm{~m}, 1 \mathrm{H}), 1.68-1.62(\mathrm{~m}$, $1 \mathrm{H}), 1.58-1.53(\mathrm{~m}, 1 \mathrm{H}), 1.51(\mathrm{dd}, J=13.4,3.5 \mathrm{~Hz}, 1 \mathrm{H}), 1.41(\mathrm{~s}, 3 \mathrm{H}), 1.39-1.36(\mathrm{~m}, 1 \mathrm{H}), 1.27-1.15(\mathrm{~m}$, $3 \mathrm{H}), 0.91(\mathrm{~d}, J=5.8 \mathrm{~Hz}, 3 \mathrm{H}), 0.88-0.82(\mathrm{~m}, 1 \mathrm{H}), 0.77(\mathrm{~d}, J=7.3 \mathrm{~Hz}, 3 \mathrm{H}) ;{ }^{13} \mathrm{C} \mathrm{NMR}\left(150 \mathrm{MHz}, \mathrm{CDCl}_{3}\right) \delta$ (ppm): 165.56, 163.09, 151.58, 142.30, 141.69, 125.34, 124.53, 123.85, 119.71, 113.06, 104.24, 102.18, 89.91, $87.88,80.78,77.25,77.04,76.82,66.39,62.61,52.37,50.60,44.02,37.37,36.29,34.45,30.58,26.09,24.61$, 24.35, 20.46, 20.33, 12.85, 11.67; ESI-HRMS [M + Na] ${ }^{+}:(m / z)$ Calcd. for $\mathrm{C}_{31} \mathrm{H}_{39} \mathrm{~N}_{3} \mathrm{O}_{8} \mathrm{Na}$ : 604.2635. Found: 604.2646 . 
8-methyl-4-((4-(2-((10S)-dihydroartemisininoxy)ethyl)-1H-1,2,3-triazol-1-yl)-methoxy)-2H-1-chromen- 2-one (5o) White solid; m.p. $84-86{ }^{\circ} \mathrm{C}$; yield $43 \%$; ${ }^{1} \mathrm{H}$ NMR $\left(600 \mathrm{MHz}, \mathrm{CDCl}_{3}\right) \delta(\mathrm{ppm}): 7.77(\mathrm{~s}, 1 \mathrm{H}), 7.61(\mathrm{~d}$, $J=7.9 \mathrm{~Hz}, 1 \mathrm{H}), 7.39(\mathrm{~d}, J=7.4 \mathrm{~Hz}, 1 \mathrm{H}), 7.13(\mathrm{t}, J=7.7 \mathrm{~Hz}, 1 \mathrm{H}), 5.85(\mathrm{~s}, 1 \mathrm{H}), 5.33(\mathrm{~d}, J=2.8 \mathrm{~Hz}, 2 \mathrm{H}), 5.15$ $(\mathrm{s}, 1 \mathrm{H}), 4.77(\mathrm{~d}, J=3.5 \mathrm{~Hz}, 1 \mathrm{H}), 4.71-4.67(\mathrm{~m}, 1 \mathrm{H}), 4.58-4.54(\mathrm{~m}, 1 \mathrm{H}), 4.33-4.27(\mathrm{~m}, 1 \mathrm{H}), 3.86-3.82(\mathrm{~m}$, $1 \mathrm{H}), 2.62-2.59(\mathrm{~m}, 1 \mathrm{H}), 2.45(\mathrm{~s}, 3 \mathrm{H}), 2.33(\mathrm{td}, J=14.1,4.0 \mathrm{~Hz}, 1 \mathrm{H}), 2.01-1.97(\mathrm{~m}, 1 \mathrm{H}), 1.86-1.81(\mathrm{~m}, 1 \mathrm{H})$, $1.65(\mathrm{dd}, J=14.0,3.6 \mathrm{~Hz}, 1 \mathrm{H}), 1.58-1.54(\mathrm{~m}, 1 \mathrm{H}), 1.51(\mathrm{dd}, J=13.4,3.5 \mathrm{~Hz}, 1 \mathrm{H}), 1.41(\mathrm{~s}, 3 \mathrm{H}), 1.40-1.35$ $(\mathrm{m}, 1 \mathrm{H}), 1.27-1.17(\mathrm{~m}, 3 \mathrm{H}), 0.90(\mathrm{~d}, J=5.8 \mathrm{~Hz}, 3 \mathrm{H}), 0.88-0.84(\mathrm{~m}, 1 \mathrm{H}), 0.77(\mathrm{~d}, J=7.3 \mathrm{~Hz}, 3 \mathrm{H}) ;{ }^{13} \mathrm{C} \mathrm{NMR}$ $\left(150 \mathrm{MHz}, \mathrm{CDCl}_{3}\right) \delta$ (ppm): 165.30, 162.70, 151.74, 141.60, 133.84, 126.28, 123.84, 123.42, 120.66, 115.15, $104.24,102.18,90.88,87.89,80.77,77.25,77.03,76.82,66.39,62.71,52.36,50.60,44.01,37.38,36.28,34.45$, 30.57, 26.09, 24.61, 24.35, 20.33, 15.76, 12.84; ESI-HRMS [M + Na] $]^{+}:(m / z)$ Calcd. for $\mathrm{C}_{30} \mathrm{H}_{37} \mathrm{~N}_{3} \mathrm{O}_{8} \mathrm{Na}$ : 590.2478. Found: 590.2477.

4-((4-(3-((10S)-dihydroartemisininoxy)propyl)-1H-1,2,3-triazol-1-yl)-methoxy)-2H-1-chromen-2-one (6j) White solid; m.p. $74-76{ }^{\circ} \mathrm{C}$; yield $47 \%$; ${ }^{1} \mathrm{H}$ NMR $\left(600 \mathrm{MHz}, \mathrm{CDCl}_{3}\right) \delta(\mathrm{ppm}): 7.79(\mathrm{dd}, J=8.0,1.6 \mathrm{~Hz}$, $1 \mathrm{H}), 7.72(\mathrm{~s}, 1 \mathrm{H}), 7.55(\mathrm{ddd}, J=8.7,7.4,1.6 \mathrm{~Hz}, 1 \mathrm{H}), 7.32(\mathrm{dd}, J=8.4,1.1 \mathrm{~Hz}, 1 \mathrm{H}), 7.26-7.23(\mathrm{~m}, 1 \mathrm{H}), 5.86$ $(\mathrm{s}, 1 \mathrm{H}), 5.41(\mathrm{~s}, 1 \mathrm{H}), 5.34(\mathrm{~s}, 2 \mathrm{H}), 4.79(\mathrm{~d}, J=3.6 \mathrm{~Hz}, 1 \mathrm{H}), 4.56-4.46(\mathrm{~m}, 2 \mathrm{H}), 3.93-3.89(\mathrm{~m}, 1 \mathrm{H}), 3.44-3.41$ $(\mathrm{m}, 1 \mathrm{H}), 2.69-2.63(\mathrm{~m}, 1 \mathrm{H}), 2.39-2.34(\mathrm{~m}, 1 \mathrm{H}), 2.27-2.20(\mathrm{~m}, 2 \mathrm{H}), 2.05-2.01(\mathrm{~m}, 1 \mathrm{H}), 1.91-1.86(\mathrm{~m}, 1 \mathrm{H})$, $1.79-1.75(\mathrm{~m}, 1 \mathrm{H}), 1.67-1.64(\mathrm{~m}, 1 \mathrm{H}), 1.51-1.46(\mathrm{~m}, 2 \mathrm{H}), 1.42(\mathrm{~s}, 3 \mathrm{H}), 1.39-1.33(\mathrm{~m}, 1 \mathrm{H}), 1.28-1.22(\mathrm{~m}$, $2 \mathrm{H}), 0.96(\mathrm{~d}, J=6.4 \mathrm{~Hz}, 3 \mathrm{H}), 0.94(\mathrm{~d}, J=7.4 \mathrm{~Hz}, 3 \mathrm{H}) ;{ }^{13} \mathrm{C} \mathrm{NMR}\left(150 \mathrm{MHz}, \mathrm{CDCl}_{3}\right) \delta(\mathrm{ppm}): 163.96$, $161.59,152.33,140.41,131.55,122.89,122.40,122.13,115.78,114.42,103.18,101.19,90.16,86.93,79.93$, 76.21, 76.00, 75.79, 63.62, 61.66, 51.47, 46.73, 43.23, 36.45, 35.33, 33.53, 29.78, 29.43, 25.12, 23.64, 23.54, 19.33, 12.07; ESI-HRMS [M + Na] ${ }^{+}:(m / z)$ Calcd. for $\mathrm{C}_{30} \mathrm{H}_{37} \mathrm{~N}_{3} \mathrm{O}_{8} \mathrm{Na}$ : 590.2478. Found: 590.2463.

7-methyl-4-((4-(3-((10S)-dihydroartemisininoxy)propyl)-1H-1,2,3-triazol-1-yl)-methoxy)-2H-1-chromen-2-one (6k) White solid; m.p. 80-82 ${ }^{\circ} \mathrm{C}$; yield 51\%; ${ }^{1} \mathrm{H}$ NMR $\left(600 \mathrm{MHz}, \mathrm{CDCl}_{3}\right) \delta(\mathrm{ppm}): 7.71(\mathrm{~s}, 1 \mathrm{H}), 7.65(\mathrm{~d}$, $J=8.1 \mathrm{~Hz}, 1 \mathrm{H}), 7.12(\mathrm{~s}, 1 \mathrm{H}), 7.05(\mathrm{~d}, J=8.1 \mathrm{~Hz}, 1 \mathrm{H}), 5.80(\mathrm{~s}, 1 \mathrm{H}), 5.41(\mathrm{~s}, 1 \mathrm{H}), 5.32(\mathrm{~s}, 2 \mathrm{H}), 4.79(\mathrm{~d}, J=3.6$ $\mathrm{Hz}, 1 \mathrm{H}), 4.53-4.46(\mathrm{~m}, 2 \mathrm{H}), 3.93-3.89(\mathrm{~m}, 1 \mathrm{H}), 3.44-3.40(\mathrm{~m}, 1 \mathrm{H}), 2.69-2.64(\mathrm{~m}, 1 \mathrm{H}), 2.44(\mathrm{~s}, 3 \mathrm{H}), 2.37$ $(\mathrm{td}, J=14.0,4.0 \mathrm{~Hz}, 1 \mathrm{H}), 2.27-2.21(\mathrm{~m}, 2 \mathrm{H}), 2.05-2.01(\mathrm{~m}, 1 \mathrm{H}), 1.91-1.86(\mathrm{~m}, 1 \mathrm{H}), 1.80-1.75(\mathrm{~m}, 2 \mathrm{H})$, $1.68-1.64(\mathrm{~m}, 1 \mathrm{H}), 1.51-1.46(\mathrm{~m}, 2 \mathrm{H}), 1.42(\mathrm{~s}, 3 \mathrm{H}), 1.28-1.24(\mathrm{~m}, 3 \mathrm{H}), 0.96(\mathrm{~d}, J=6.4 \mathrm{~Hz}, 3 \mathrm{H}), 0.94(\mathrm{~d}, J$ $=7.3 \mathrm{~Hz}, 3 \mathrm{H}) ;{ }^{13} \mathrm{C} \mathrm{NMR}\left(150 \mathrm{MHz}, \mathrm{CDCl}_{3}\right) \delta$ (ppm): $\delta 164.21,161.95,152.44,142.81,140.51,124.11$, $122.39,121.82$, 115.88, 111.91, 103.19, 101.18, 89.25, 86.93, 79.94, 76.20, 75.99, 75.78, 63.62, 61.55, 51.47, 46.73, 43.24, 36.44, 35.33, 33.53, 29.78, 29.42, 25.12, 23.63, 23.53, 20.72, 19.33, 12.07; ESI-HRMS [M + $\mathrm{Na}]^{+}:(m / z)$ Calcd. for $\mathrm{C}_{31} \mathrm{H}_{39} \mathrm{~N}_{3} \mathrm{O}_{8} \mathrm{Na}$ : 604.2635. Found: 604.2617.

5,7-dimethyl-4-((4-(3-((10S)-dihydroartemisininoxy)propyl)-1H-1,2,3-triazol-1-yl)-methoxy)-2H-1-chromen2-one (61) White solid; m.p. 86-88 ${ }^{\circ} \mathrm{C}$; yield $42 \% ;{ }^{1} \mathrm{H}$ NMR (600 MHz, $\left.\mathrm{CDCl}_{3}\right) \delta(\mathrm{ppm}): 7.68(\mathrm{~s}, 1 \mathrm{H})$, $6.98(\mathrm{~s}, 1 \mathrm{H}), 6.83(\mathrm{~s}, 1 \mathrm{H}), 5.74(\mathrm{~s}, 1 \mathrm{H}), 5.40(\mathrm{~s}, 1 \mathrm{H}), 5.28(\mathrm{~s}, 2 \mathrm{H}), 4.78(\mathrm{~d}, J=3.7 \mathrm{~Hz}, 1 \mathrm{H}), 4.53-4.48(\mathrm{~m}$, $2 \mathrm{H}), 3.91-3.87(\mathrm{~m}, 1 \mathrm{H}), 3.42-3.38(\mathrm{~m}, 1 \mathrm{H}), 2.69-2.64(\mathrm{~m}, 1 \mathrm{H}), 2.53(\mathrm{~s}, 3 \mathrm{H}), 2.40-2.33(\mathrm{~m}, 4 \mathrm{H}), 2.25-2.19$ $(\mathrm{m}, 2 \mathrm{H}), 2.05-2.01(\mathrm{~m}, 1 \mathrm{H}), 1.91-1.86(\mathrm{~m}, 1 \mathrm{H}), 1.80-1.77(\mathrm{~m}, 1 \mathrm{H}), 1.76-1.73(\mathrm{~m}, 1 \mathrm{H}), 1.67-1.64(\mathrm{~m}, 1 \mathrm{H})$, 1.51-1.47 (m, 2H), $1.42(\mathrm{~s}, 3 \mathrm{H}), 1.30-1.21(\mathrm{~m}, 3 \mathrm{H}), 0.96(\mathrm{~d}, J=6.4 \mathrm{~Hz}, 3 \mathrm{H}), 0.94(\mathrm{~d}, J=7.4 \mathrm{~Hz}, 3 \mathrm{H}) ;{ }^{13} \mathrm{C}$ NMR (150 MHz, $\mathrm{CDCl}_{3}$ ) $\delta$ (ppm): 166.99, 161.73, 153.90, 141.72, 140.46, 135.57, 127.92, 122.26, 114.43, $110.63,103.18,101.15,89.14,86.91,79.93,76.21,76.00,75.78,63.49,61.58,51.46,46.66,43.23,36.46,35.33$, $33.53,29.78,29.42,25.11,23.64,23.54,22.46,20.35,19.33,12.08$; ESI-HRMS $[\mathrm{M}+\mathrm{Na}]^{+}:(\mathrm{m} / \mathrm{z})$ Calcd. for $\mathrm{C}_{32} \mathrm{H}_{41} \mathrm{~N}_{3} \mathrm{O}_{8} \mathrm{Na}$ : 618.2791. Found: 618.2827.

6,8-dimethyl-4-((4-(3-((10S)-dihydroartemisininoxy)propyl)-1H-1,2,3-triazol-1-yl)-methoxy)-2H-1-chromen2-one (6m) White solid; m.p. 90-92 ${ }^{\circ} \mathrm{C}$; yield 55\%; ${ }^{1} \mathrm{H}$ NMR $\left(600 \mathrm{MHz}, \mathrm{CDCl}_{3}\right) \delta(\mathrm{ppm}): 7.71(\mathrm{~s}, 1 \mathrm{H})$, $7.40(\mathrm{~s}, 1 \mathrm{H}), 7.21(\mathrm{~s}, 1 \mathrm{H}), 5.82(\mathrm{~s}, 1 \mathrm{H}), 5.41(\mathrm{~s}, 1 \mathrm{H}), 5.32(\mathrm{~s}, 2 \mathrm{H}), 4.79(\mathrm{~d}, J=3.6 \mathrm{~Hz}, 1 \mathrm{H}), 4.55-4.46(\mathrm{~m}$, $2 \mathrm{H}), 3.94-3.90(\mathrm{~m}, 1 \mathrm{H}), 3.44-3.40(\mathrm{~m}, 1 \mathrm{H}), 2.69-2.63(\mathrm{~m}, 1 \mathrm{H}), 2.40(\mathrm{~s}, 3 \mathrm{H}), 2.39-2.34(\mathrm{~m}, 1 \mathrm{H}), 2.33(\mathrm{~s}$, $3 \mathrm{H}), 2.27-2.21(\mathrm{~m}, 2 \mathrm{H}), 2.06-2.01(\mathrm{~m}, 1 \mathrm{H}), 1.91-1.86(\mathrm{~m}, 1 \mathrm{H}), 1.79-1.77(\mathrm{~m}, 1 \mathrm{H}), 1.76-1.73(\mathrm{~m}, 1 \mathrm{H})$, $1.67-1.63(\mathrm{~m}, 1 \mathrm{H}), 1.51-1.45(\mathrm{~m}, 2 \mathrm{H}), 1.42(\mathrm{~s}, 3 \mathrm{H}), 1.37-1.35(\mathrm{~m}, 1 \mathrm{H}), 1.28-1.22(\mathrm{~m}, 2 \mathrm{H}), 0.95(\mathrm{~d}, J=6.4$ $\mathrm{Hz}, 3 \mathrm{H}), 0.94(\mathrm{~d}, J=7.4 \mathrm{~Hz}, 3 \mathrm{H}) ;{ }^{13} \mathrm{C} \mathrm{NMR}\left(150 \mathrm{MHz}, \mathrm{CDCl}_{3}\right) \delta(\mathrm{ppm}): 165.37,163.02,149.90,141.55$, 
$134.97,133.07,125.88,123.45,120.35,114.83,104.21,102.21,90.79,87.96,80.97,77.25,77.04,76.83,64.68$, 62.56, 52.51, 47.77, 44.27, 37.47, 36.37, 34.56, 30.82, 30.47, 26.15, 24.67, 24.57, 20.83, 20.36, 15.66, 13.11; ESI-HRMS $\left[\mathrm{M}+\mathrm{Na}^{+}:(\mathrm{m} / \mathrm{z})\right.$ Calcd. for $\mathrm{C}_{32} \mathrm{H}_{41} \mathrm{~N}_{3} \mathrm{O}_{8} \mathrm{Na}$ : 618.2791. Found: 618.2808.

7,8-dimethyl-4-((4-(3-((10S)-dihydroartemisininoxy)propyl)-1H-1,2,3-triazol-1-yl)-methoxy)-2H-1-chromen2-one (6n) White solid; m.p. $115-117{ }^{\circ} \mathrm{C}$; yield 44\%; ${ }^{1} \mathrm{H} \mathrm{NMR}\left(600 \mathrm{MHz}, \mathrm{CDCl}_{3}\right) \delta$ (ppm): $7.71(\mathrm{~s}, 1 \mathrm{H})$, $7.52(\mathrm{~d}, J=8.1 \mathrm{~Hz}, 1 \mathrm{H}), 7.04(\mathrm{~d}, J=8.1 \mathrm{~Hz}, 1 \mathrm{H}), 5.80(\mathrm{~s}, 1 \mathrm{H}), 5.40(\mathrm{~s}, 1 \mathrm{H}), 5.32(\mathrm{~s}, 2 \mathrm{H}), 4.79(\mathrm{~d}, J=3.5$ $\mathrm{Hz}, 1 \mathrm{H}), 4.56-4.45$ (m, 2H), 3.93-3.89 (m, 1H), 3.44-3.40 (m, 1H), 2.69-2.64 (m, 1H), 2.39-2.34 (m, 7H), 2.27-2.19 (m, 2H), 2.06-2.01 (m, 1H), 1.92-1.86 (m, 1H), 1.81-1.77 (m, 1H), $1.74(\mathrm{dd}, J=13.4,3.5 \mathrm{~Hz}, 1 \mathrm{H})$, $1.67-1.63(\mathrm{~m}, 1 \mathrm{H}), 1.52-1.45(\mathrm{~m}, 2 \mathrm{H}), 1.42(\mathrm{~s}, 3 \mathrm{H}), 1.39-1.34(\mathrm{~m}, 1 \mathrm{H}), 1.27-1.24(\mathrm{~m}, 2 \mathrm{H}), 0.96(\mathrm{~d}, J=6.4$ $\mathrm{Hz}, 3 \mathrm{H}), 0.94$ (d, $J=7.4 \mathrm{~Hz}, 3 \mathrm{H}) ;{ }^{13} \mathrm{C} \mathrm{NMR}\left(150 \mathrm{MHz}, \mathrm{CDCl}_{3}\right) \delta(\mathrm{ppm}): 165.61,163.15,151.58,142.28$, 141.66, 125.37, 124.51, 123.38, 119.78, 113.07, 104.21, 102.21, 89.92, 87.96, 80.97, 77.25, 77.04, 76.82, 64.66, 62.60, 52.51, 47.76, 44.27, 37.47, 36.37, 34.56, 30.82, 30.46, 26.15, 24.67, 24.57, 20.46, 20.37, 13.11, 11.67; ESI-HRMS $[\mathrm{M}+\mathrm{Na}]^{+}:(\mathrm{m} / z)$ Calcd. for $\mathrm{C}_{32} \mathrm{H}_{41} \mathrm{~N}_{3} \mathrm{O}_{8} \mathrm{Na}: 618.2791$. Found: 618.2793.

8-methyl-4-((4-(3-((10S)-dihydroartemisininoxy)propyl)-1H-1,2,3-triazol-1-yl)-methoxy)-2H-1-chromen-2-one (6o) White solid; m.p. $143-145^{\circ} \mathrm{C}$; yield 38\%; ${ }^{1} \mathrm{H} \mathrm{NMR}\left(600 \mathrm{MHz}, \mathrm{CDCl}_{3}\right) \delta$ (ppm): $7.71(\mathrm{~s}, 1 \mathrm{H}), 7.63(\mathrm{~d}$, $J=8.0 \mathrm{~Hz}, 1 \mathrm{H}), 7.39(\mathrm{~d}, J=7.3 \mathrm{~Hz}, 1 \mathrm{H}), 7.14(\mathrm{t}, J=7.7 \mathrm{~Hz}, 1 \mathrm{H}), 5.85(\mathrm{~s}, 1 \mathrm{H}), 5.40(\mathrm{~s}, 1 \mathrm{H}), 5.33(\mathrm{~s}, 2 \mathrm{H})$, $4.79(\mathrm{~d}, J=3.7 \mathrm{~Hz}, 1 \mathrm{H}), 4.55-4.46(\mathrm{~m}, 2 \mathrm{H}), 3.93-3.89(\mathrm{~m}, 1 \mathrm{H}), 3.44-3.40(\mathrm{~m}, 1 \mathrm{H}), 2.70-2.63(\mathrm{~m}, 1 \mathrm{H}), 2.45$ $(\mathrm{s}, 3 \mathrm{H}), 2.37(\mathrm{td}, J=14.0,3.9 \mathrm{~Hz}, 1 \mathrm{H}), 2.28-2.19(\mathrm{~m}, 2 \mathrm{H}), 2.05-2.01(\mathrm{~m}, 1 \mathrm{H}), 1.92-1.86(\mathrm{~m}, 1 \mathrm{H}), 1.81-1.72$ $(\mathrm{m}, 2 \mathrm{H}), 1.67-1.64(\mathrm{~m}, 1 \mathrm{H}), 1.53-1.46(\mathrm{~m}, 2 \mathrm{H}), 1.42(\mathrm{~s}, 3 \mathrm{H}), 1.39-1.33(\mathrm{~m}, 1 \mathrm{H}), 1.30-1.22(\mathrm{~m}, 2 \mathrm{H}), 0.96(\mathrm{~d}$, $J=6.4 \mathrm{~Hz}, 3 \mathrm{H}), 0.94(\mathrm{~d}, J=7.4 \mathrm{~Hz}, 3 \mathrm{H}) ;{ }^{13} \mathrm{C} \mathrm{NMR}\left(150 \mathrm{MHz}, \mathrm{CDCl}_{3}\right) \delta(\mathrm{ppm}): 165.35,162.77,151.73$, 141.56, 133.82, 126.25, 123.45, 123.40, 120.73, 115.17, 104.22, 102.21, 90.89, 87.96, 80.97, 77.24, 77.03, 76.82, 64.65, 62.69, 52.51, 47.76, 44.27, 37.48, 36.37, 34.56, 30.82, 30.46, 26.15, 24.67, 24.57, 20.37, 15.76, 13.11; ESI-HRMS [M + Na] $]^{+}:(m / z)$ Calcd. for $\mathrm{C}_{31} \mathrm{H}_{39} \mathrm{~N}_{3} \mathrm{O}_{8} \mathrm{Na}$ : 604.2635. Found: 604.2646.

6-methyl-4-((4-(3-((10S)-dihydroartemisininoxy)propyl)-1H-1,2,3-triazol-1-yl)-methoxy)-2H-1-chromen-2-one (6p) White solid; m.p. 80-82 ${ }^{\circ} \mathrm{C}$; yield 45\%; ${ }^{1} \mathrm{H}$ NMR (600 MHz, $\left.\mathrm{CDCl}_{3}\right) \delta$ (ppm): $7.72(\mathrm{~s}, 1 \mathrm{H}), 7.56(\mathrm{~s}$, $1 \mathrm{H}), 7.35(\mathrm{dd}, J=8.5,2.0 \mathrm{~Hz}, 1 \mathrm{H}), 7.21(\mathrm{~d}, J=8.4 \mathrm{~Hz}, 1 \mathrm{H}), 5.84(\mathrm{~s}, 1 \mathrm{H}), 5.41(\mathrm{~s}, 1 \mathrm{H}), 5.33(\mathrm{~s}, 2 \mathrm{H}), 4.80(\mathrm{~d}$, $J=3.6 \mathrm{~Hz}, 1 \mathrm{H}), 4.55-4.47(\mathrm{~m}, 2 \mathrm{H}), 3.94-3.90(\mathrm{~m}, 1 \mathrm{H}), 3.45-3.41(\mathrm{~m}, 1 \mathrm{H}), 2.70-2.64(\mathrm{~m}, 1 \mathrm{H}), 2.40-2.33(\mathrm{~m}$, $4 \mathrm{H}), 2.27-2.21(\mathrm{~m}, 2 \mathrm{H}), 2.06-2.01(\mathrm{~m}, 1 \mathrm{H}), 1.91-1.87(\mathrm{~m}, 1 \mathrm{H}), 1.80-1.73(\mathrm{~m}, 2 \mathrm{H}), 1.65(\mathrm{dd}, J=13.3,3.4 \mathrm{~Hz}$, $1 \mathrm{H}), 1.53-1.46(\mathrm{~m}, 2 \mathrm{H}), 1.42(\mathrm{~s}, 3 \mathrm{H}), 1.38-1.34(\mathrm{~m}, 1 \mathrm{H}), 1.28-1.22(\mathrm{~m}, 2 \mathrm{H}), 0.96(\mathrm{~d}, J=6.4 \mathrm{~Hz}, 3 \mathrm{H}), 0.94(\mathrm{~d}$, $J=7.3 \mathrm{~Hz}, 3 \mathrm{H}) ;{ }^{13} \mathrm{C} \mathrm{NMR}\left(150 \mathrm{MHz}, \mathrm{CDCl}_{3}\right) \delta(\mathrm{ppm}): 165.02,162.88,151.52,141.46,133.69,133.59$, $123.52,122.80,116.56,115.08,104.22,102.22,91.11,87.97,80.97,77.24,77.03,76.82,64.68,62.60,52.51$, $47.80,44.27,37.48,36.37,34.57,30.82,30.48,26.15,24.67,24.58,20.90,20.37,13.12$; ESI-HRMS [M + $\mathrm{Na}]^{+}:(m / z)$ Calcd. for $\mathrm{C}_{31} \mathrm{H}_{39} \mathrm{~N}_{3} \mathrm{O}_{8} \mathrm{Na}$ : 604.2635. Found: 604.2621.

\subsection{Biology}

\subsubsection{Storage and Preparation of Samples}

All the target compounds were dissolved in dimethylsulfoxide and storage under $-20^{\circ} \mathrm{C}$. They get to be diluted to different concentration when they will be used.

\subsubsection{Cell Culture}

After recovery, the cells were cultured in 96-well plates for $24 \mathrm{~h}$ at $37^{\circ} \mathrm{C}$ in a humidified atmosphere with $95 \%$ air and $5 \% \mathrm{CO}_{2}$. After treated with different tested compounds, the hypoxia groups were placed in a sealed hypoxia incubator chamber (Stemcell Technologies, Inc., Vancouver, BC, Canada) filled with $5 \% \mathrm{CO}_{2}$ and $95 \% \mathrm{~N}_{2}$ for $24 \mathrm{~h}$, and then transferred to the incubator chamber filled with air for $72 \mathrm{~h}$. On the contrary, the normoxia groups were cultured under air condition for $96 \mathrm{~h}$.

Cancer cells HT-29 (Human Colorectal Adenocarcinoma cell line), MDA-MB-231 (Human Breast Cancer cell line), HCT-116 (Human Colorectal Carcinoma cell line), and A549 (Human Lung Adenocarcinomic cell line) were from ATCC. 


\subsubsection{MTT Assay}

When the adherent cells reached $80 \%$ confluence, the culture medium was discarded. The cells were digested by trypsin and collected after centrifugation. The fresh culture medium was gently blown into it to form single-cell suspension. Cell suspension will be diluted to $1.5-3 \times 10^{4}$ cells $/ \mathrm{mL}$. Each hole of 96-well plates was added $100 \mu \mathrm{L}$ cell suspension and incubated for $24 \mathrm{~h}\left(5 \% \mathrm{CO}_{2} ; 37^{\circ} \mathrm{C}\right)$. Then the holes were added different concentrations of tested compounds. The early screening concentration is set to $100 \mu \mathrm{M}, 50 \mu \mathrm{M}, 25 \mu \mathrm{M}, 12.5 \mu \mathrm{M}$, and $6.25 \mu \mathrm{M}$. Three replicates were made for each concentration of the tested compounds. After the cells were grown for 96h, $20 \mu \mathrm{L}$ MTT ( $5 \mathrm{mg} / \mathrm{mL})$ was added to each well and incubated for $4 \mathrm{~h}$. The medium was discarded and each well was added $100 \mu \mathrm{L}$ DMSO to dissolve the formazan blue. Absorbance was measured at $570 \mathrm{~nm}$ with a microplate reader (Synergy-HT, BioTek Instruments, Winooski, VT, USA).

Hypoxia condition: The cells were treated with different concentration of tested compounds, placed in hypoxia chamber (Catalog Number 27310, Stemcell Technologies, Inc., Vancouver, BC, Canada), and incubated for $24 \mathrm{~h}\left(5 \%\right.$ air; $\left.95 \% \mathrm{~N}_{2} ; 37^{\circ} \mathrm{C}\right)$. Then the cells were placed in normoxia condition $\left(5 \% \mathrm{CO}_{2} ; 37^{\circ} \mathrm{C}\right)$ and incubated for $72 \mathrm{~h}$.

\subsubsection{Preparation of N9 Cells}

The murine microglial cell line N9 was a kind gift from Dr. P. Ricciardi-Castagnoli (Universita Degli Studi di Milano-Bicocca, Milan, Italy).

N9 cells, which were in the logarithmic phase, were incubated for $24 \mathrm{~h}$ by adherent culture. Subsequently, the medium was changed to new one without serum. The cells were treated with different concentration of tested compounds. After specific time in the LPS condition, the supernatants were collected and analyzed.

\subsubsection{Nitrite Measurement}

The nitrite levels in medium were determined by Griess reaction. The absorbance was measured at $540 \mathrm{~nm}$ using a microplate reader.

\subsubsection{NO Capture Analysis}

SNP was dissolved in PBS to prepare the $100 \mathrm{mM}$ stock solution. In this experiment, SNP solution of $25 \mu \mathrm{L}$ was added to $975 \mu \mathrm{L}$ PBS solution which included different concentration of tested compounds. After 60 min under r.t. condition, the concentration of $\mathrm{NO}_{2}{ }^{-}$was tested using Griess assay.

\subsubsection{Evaluation of Inflammatory Mediator}

The secreted level of TNF- $\alpha$ and IL- 6 was measured using mouse Th1/Th2/Th17 Cytokine Kit, purchased from BD Pharningen. The data was analyzed by FCAP Array v3.0. IL-2, IL-4, IL-10, IL-17A, and IFN- $\gamma$ were not detected in the experiment.

\subsubsection{Molecular Docking Simulations}

The crystallographic structure of TLR4/MD-2 complex was retrieved from the Protein DataBank (PDB ID: 3VQ2), which was optimized by removing water molecules, cofactors and heteroatoms. Receptor grid was generally around the MD-2 active site. Docking calculations were accomplished using AutoDock4. The docking results were further analyzed and visually optimized by Discovery Studio 4.0 and PyMOL.

Supplementary Materials: The H and 13 C NMR spectra of synthesized compounds are available online.

Author Contributions: H.Y. performed experiments, analyzed data, and drafted the manuscript. Z.H. performed experiments, analyzed data, and revised the manuscript. X.Y. performed experiments. Y.M. and C.G. conceived the work, gave critical comments, and revised the manuscript. 
Funding: We greatly appreciate the funding support for this research provided by the National Natural Science Foundation of China (Grant No. 81573292).

Conflicts of Interest: The authors declare no conflict of interest.

$\begin{array}{ll}\text { Abbreviations } \\ \text { DHA } & \text { Dihydroartemisinin } \\ \text { DCH } & \text { Dihydroartemisinin-Coumarin hydrids } \\ \text { CRF } & \text { Cancer-related fatigue } \\ \text { DOX } & \text { Doxorubicin } \\ \text { CNS } & \text { Central nervous system } \\ \text { SNP } & \text { Sodium nitroprusside } \\ \text { LPS } & \text { Lipopolysaccharide } \\ \text { TLR4 } & \text { Toll-like receptor } 4\end{array}$

\section{References}

1. Tsuji, E.; Hiki, N.; Nomura, S.; Fukushima, R.; Kojima, J.; Ogawa, T.; Mafune, K.; Mimura, Y.; Kaminishi, M. Simultaneous onset of acute inflammatory response, sepsis-like symptoms and intestinal mucosal injury after cancer chemotherapy. Int. J. Cancer 2003, 107, 303-308. [CrossRef] [PubMed]

2. Cerci, C.; Ergin, C.; Eroglu, E.; Agalar, C.; Agalar, F.; Cerci, S.; Bulbul, M. Effects of granulocyte-colony stimulating factor on peritoneal defense mechanisms and bacterial translocation after administration of systemic chemotherapy in rats. World J. Gastroenterol. 2007, 13, 2596-2599. [CrossRef] [PubMed]

3. Rivest, S. Molecular insights on the cerebral innate immune system. Brain Behav. Immun. 2003, 17, 13-19. [CrossRef]

4. Norden, D.M.; Bicer, S.; Clark, Y.; Jing, R.; Henry, C.J.; Wold, L.E.; Reiser, P.J.; Godbout, J.P.; McCarthy, D.O. Tumor growth increases neuroinflammation, fatigue and depressive-like behavior prior to alterations in muscle function. Brain Behav. Immun. 2015, 43, 76-85. [CrossRef] [PubMed]

5. Bower, J.E.; Lamkin, D.M. Inflammation and cancer-related fatigue: Mechanisms, contributing factors, and treatment implications. Brain Behav. Immun. 2013, 30, S48-S57. [CrossRef]

6. Perry, V.H.; Gordon, S. Macrophages and microglia in the nervous system. Trends Neurosci. 1988, 11, $273-277$. [CrossRef]

7. Kreutzberg, G.W. Microglia: A sensor for pathological events in the CNS. Trends Neurosci. 1996, 19, 312-318. [CrossRef]

8. Colton, C.A.; Gilbert, D.L. Production of superoxide anions by a CNS macrophage, the microglia. FEBS Lett. 1987, 223, 284-288. [CrossRef]

9. Banati, R.B.; Gehrmann, J.; Schubert, P.; Kreutzberg, G.W. Cytotoxicity of microglia. Glia 1993, 7, 111-118. [CrossRef]

10. Lissauer, M.E.; Johnson, S.B.; Bochicchio, G.V.; Feild, C.J.; Cross, A.S.; Hasday, J.D.; Whiteford, C.C.; Nussbaumer, W.A.; Towns, M.; Scalea, T.M. Differential expression of toll-like receptor genes: Sepsis compared with sterile inflammation 1 day before sepsis diagnosis. Shock 2009, 31, 238-244. [CrossRef]

11. Steiner, A.A.; Chakravarty, S.; Rudaya, A.Y.; Herkenham, M.; Romanovsky, A.A. Bacterial lipopolysaccharide fever is initiated via Toll-like receptor 4 on hematopoietic cells. Blood 2006, 107, 4000-4002. [CrossRef]

12. Shimazu, R.; Akashi, S.; Ogata, H.; Nagai, Y.; Fukudome, K.; Miyake, K.; Kimoto, M. MD-2, a Molecule that Confers Lipopolysaccharide Responsiveness on Toll-like Receptor 4. J. Exp. Med. 1999, 189, 1777-1782. [CrossRef] [PubMed]

13. Nagai, Y.; Akashi, S.; Nagafuku, M.; Ogata, M.; Iwakura, Y.; Akira, S.; Kitamura, T.; Kosugi, A.; Kimoto, M.; Miyake, K. Essential role of MD-2 in LPS responsiveness and TLR4 distribution. Nat. Immunol. 2002, 3, 667-672. [CrossRef] [PubMed]

14. Inohara, N.; Nuñez, G. ML-A conserved domain involved in innate immunity and lipid metabolism. Trends Biochem. Sci. 2002, 27, 219-221. [CrossRef]

15. Viriyakosol, S.; Tobias, P.S.; Kitchens, R.L.; Kirkland, T.N. MD-2 binds to bacterial lipopolysaccharide. J. Biol. Chem. 2001, 276, 38044-38051. [PubMed] 
16. Navaratnam, V.; Mansor, S.M.; Sit, N.W.; Grace, J.; Li, Q.; Olliaro, P. Pharmacokinetics of artemisinin-type compounds. Clin. Pharmacokinet. 2000, 39, 255-270. [CrossRef] [PubMed]

17. Balint, G.A. Artemisinin and its derivatives: An important new class of antimalarial agents. Pharmacol. Ther. 2001, 90, 261-265. [CrossRef]

18. Chen, H.; Gu, S.; Dai, H.; Li, X.; Zhang, Z. Dihydroartemisinin Sensitizes Human Lung Adenocarcinoma A549 Cells to Arsenic Trioxide via Apoptosis. Biol. Trace Elem. Res. 2017, 179, 203-212. [CrossRef]

19. Cao, L.; Duanmu, W.; Yin, Y.; Zhou, Z.; Ge, H.; Chen, T.; Tan, L.; Yu, A.; Hu, R.; Fei, L.; et al. Dihydroartemisinin exhibits anti-glioma stem cell activity through inhibiting p-AKT and activating caspase-3. Die Pharm. 2014, $69,752-758$.

20. Zhang, Z.; Guo, M.; Zhao, S.; Shao, J.; Zheng, S. ROS-JNK1/2-dependent activation of autophagy is required for the induction of anti-inflammatory effect of dihydroartemisinin in liver fibrosis. Free Radic. Biol. Med. 2016, 101, 272-283. [CrossRef]

21. Jiang, L.B.; Meng, D.H.; Lee, S.M.; Liu, S.H.; Xu, Q.T.; Wang, Y.; Zhang, J. Dihydroartemisinin inhibits catabolism in rat chondrocytes by activating autophagy via inhibition of the NF-kappaB pathway. Sci. Rep. 2016, 6, 38979. [CrossRef]

22. Huang, X.; Xie, Z.; Liu, F.; Han, C.; Zhang, D.; Wang, D.; Bao, X.; Sun, J.; Wen, C.; Fan, Y. Dihydroartemisinin inhibits activation of the Toll-like receptor 4 signaling pathway and production of type I interferon in spleen cells from lupus-prone MRL/lpr mice. Int. Immunopharmacol. 2014, 22, 266-272. [CrossRef]

23. Witaicenis, A.; de Oliveira, E.C.S.; Tanimoto, A.; Zorzella-Pezavento, S.F.G.; de Oliveira, S.L.; Sartori, A.; Di Stasi, L.C. 4-methylesculetin, a coumarin derivative, ameliorates dextran sulfate sodium-induced intestinal inflammation. Chem. Biol. Interact. 2018, 280, 59-63. [CrossRef] [PubMed]

24. Chougala, B.M.; Samundeeswari, S.; Holiyachi, M.; Naik, N.S.; Shastri, L.A.; Dodamani, S.; Jalalpure, S.; Dixit, S.R.; Joshi, S.D.; Sunagar, V.A. Green, unexpected synthesis of bis-coumarin derivatives as potent anti-bacterial and anti-inflammatory agents. Eur. J. Med. Chem. 2018, 143, 1744-1756. [CrossRef] [PubMed]

25. Emami, S.; Dadashpour, S. Current developments of coumarin-based anti-cancer agents in medicinal chemistry. Eur. J. Med. Chem. 2015, 102, 611-630. [CrossRef] [PubMed]

26. Basanagouda, M.; Jambagi, V.B.; Barigidad, N.N.; Laxmeshwar, S.S.; Devaru, V.; Narayanachar. Synthesis, structure-activity relationship of iodinated-4-aryloxymethyl-coumarins as potential anti-cancer and anti-mycobacterial agents. Eur. J. Med. Chem. 2014, 74, 225-233. [CrossRef]

27. Devji, T.; Reddy, C.; Woo, C.; Awale, S.; Kadota, S.; Carrico-Moniz, D. Pancreatic anticancer activity of a novel geranylgeranylated coumarin derivative. Bioorg. Med. Chem. Lett. 2011, 21, 5770-5773. [CrossRef] [PubMed]

28. Bronikowska, J.; Szliszka, E.; Jaworska, D.; Czuba, Z.P.; Krol, W. The coumarin psoralidin enhances anticancer effect of tumor necrosis factor-related apoptosis-inducing ligand (TRAIL). Molecules 2012, 17, 6449-6464. [CrossRef] [PubMed]

29. Reddy, N.S.; Gumireddy, K.; Mallireddigari, M.R.; Cosenza, S.C.; Venkatapuram, P.; Bell, S.C.; Reddy, E.P.; Reddy, M.V. Novel coumarin-3-(N-aryl)carboxamides arrest breast cancer cell growth by inhibiting ErbB-2 and ERK1. Bioorg. Med. Chem. 2005, 13, 3141-3147. [CrossRef]

30. Harada, K.; Kubo, H.; Tomigahara, Y.; Nishioka, K.; Takahashi, J.; Momose, M.; Inoue, S.; Kojima, A. Coumarins as novel 17beta-hydroxysteroid dehydrogenase type 3 inhibitors for potential treatment of prostate cancer. Bioorg. Med. Chem. Lett. 2010, 20, 272-275. [CrossRef]

31. Vijay Avin, B.R.; Thirusangu, P.; Lakshmi Ranganatha, V.; Firdouse, A.; Prabhakar, B.T.; Khanum, S.A. Synthesis and tumor inhibitory activity of novel coumarin analogs targeting angiogenesis and apoptosis. Eur. J. Med. Chem. 2014, 75, 211-221. [CrossRef]

32. Jin, J.; Yu, X.; Hu, Z.; Tang, S.; Zhong, X.; Xu, J.; Shang, P.; Huang, Y.; Liu, H. Isofraxidin targets the TLR4/MD-2 axis to prevent osteoarthritis development. Food Funct. 2018, 9, 5641-5652. [CrossRef]

33. Liu, J.; Chen, Q.; Jian, Z.; Xiong, X.; Shao, L.; Jin, T.; Zhu, X.; Wang, L. Daphnetin Protects against Cerebral Ischemia/Reperfusion Injury in Mice via Inhibition of TLR4/NF-kappaB Signaling Pathway. Biomed. Res. Int. 2016, 2016, 2816056. [CrossRef]

34. Tian, Y.; Liang, Z.; Xu, H.; Mou, Y.; Guo, C. Design, Synthesis and Cytotoxicity of Novel Dihydroartemisinin-Coumarin Hybrids via Click Chemistry. Molecules 2016, 21, 758. [CrossRef]

35. Yu, H.; Hou, Z.; Tian, Y.; Mou, Y.; Guo, C. Design, synthesis, cytotoxicity and mechanism of novel dihydroartemisinin-coumarin hybrids as potential anti-cancer agents. Eur. J. Med. Chem. 2018, 151, 434-449. [CrossRef] 
36. Tan, Y.; Yang, X.-D.; Liu, W.-J.; Sun, X.-W. Novel one-pot asymmetric cascade approach toward densely substituted enantioenriched $\alpha$-methylene- $\gamma$-lactams. Tetrahedron Lett. 2014, 55, 6105-6108. [CrossRef]

37. Pechmann, H.V. Berichte der deutschen chemischen. Gesellschaft 1884, 17, 929.

38. Ji, Q.; Ge, Z.; Ge, Z.; Chen, K.; Wu, H.; Liu, X.; Huang, Y.; Yuan, L.; Yang, X.; Liao, F. Synthesis and biological evaluation of novel phosphoramidate derivatives of coumarin as chitin synthase inhibitors and antifungal agents. Eur. J. Med. Chem. 2016, 108, 166-176. [CrossRef]

39. Ohto, U.; Fukase, K.; Miyake, K.; Shimizu, T. Structural basis of species-specific endotoxin sensing by innate immune receptor TLR4/MD-2. Proc. Natl. Acad. Sci. USA 2012, 109, 7421-7426. [CrossRef]

Sample Availability: Not available.

(C) 2019 by the authors. Licensee MDPI, Basel, Switzerland. This article is an open access article distributed under the terms and conditions of the Creative Commons Attribution (CC BY) license (http://creativecommons.org/licenses/by/4.0/). 